\title{
Patterns and mechanisms of heavy metal accumulation and tolerance in two terrestrial moss species with contrasting habitat specialization
}

\author{
M. Teresa Boquete ${ }^{1}$, Ingeborg Lang ${ }^{2}$, Marieluise Weidinger ${ }^{3}$, Christina Richards ${ }^{4}$, and \\ Conchita Alonso ${ }^{1}$ \\ ${ }^{1}$ Estación Biológica de Doñana \\ ${ }^{2}$ University of Vienna Faculty of Life Sciences \\ ${ }^{3}$ Universitiy of Vienna \\ ${ }^{4}$ University of South Florida
}

October 20, 2020

\begin{abstract}
Phenotypic variation in natural populations is crucial for rapid adjustment to challenging environmental conditions such as exposure to heavy metal pollution. Hence, the study of variation in traits related to plant response to heavy metal stress provides valuable insight into the likelihood of a population's survival. We investigate the patterns and mechanisms of intraspecific phenotypic variation for heavy metal accumulation and tolerance in bryophytes, one of the most resilient yet relatively understudied taxa. Two terrestrial mosses exposed to $\mathrm{Cd}$ and $\mathrm{Cu}$ in the laboratory, the heavy metal specialist Scopelophila cataractae and the facultative metallophyte Ceratodon purpureus, showed intraspecific differences in tolerance to these metals. Only the heavy metal specialist showed differences in accumulation which in the case of $\mathrm{Cu}$ could be associated to preferential relocation towards the stem to protect their main photosynthetic organs. We also report the first evidence for sexual dimorphism for Cd tolerance in C. purpureus (females being more tolerant than males). Our results provide support for high variation in the capacity of bryophytes to respond to environmental challenge despite potentially low levels of genetic variation and lack of previous exposure to stress, as well as evidence for metal-dependent, sex-specific differences in heavy metal tolerance in bryophytes.
\end{abstract}

\section{Acknowledgements}

We thank Dr. Carlos M. Herrera for his advice throughout the development of the project and for critically reviewing the manuscript; Dr. Jonathan A. Shaw and Dr. Blanka Aguero for their help with sample localization and collection; Dr. Stuart F. McDaniel for providing material from lab-maintained populations of C. purpureus ; Luiza Silva Simoes and Olivia Santiago for help during laboratory work at USF; Dr. Zachary D. Atlas and Dr. David B. Lewis for providing support and infrastructure for soil analyses at USF. SEM-EDX was performed at the Core Facility Cell Imaging \& Ultrastructure Research, University of Vienna - member of the Vienna Life-Science Instruments (VLSI) and we thank Dr. Irene Lichtscheidl for her support. This research has received funding from the European Union's Horizon 2020 research and innovation programme under the Marie Skłodowska-Curie grant agreement No 704141-BryOmics.

\section{Introduction}

The environment poses continuous challenges to all living organisms. Environmental heterogeneity is ubiquitous, as gradients and spatial variation in temperature, radiation, water availability, and soil composition and chemistry exist at different spatial and temporal scales (Bell et al., 1993; Pigliucci, 2001). In addition, 
anthropogenic activities change the environment altering climate, the structure of the landscape, the major biogeochemical cycles, and also introducing pollutants into the ecosystems (Anderson, Willis, \& MitchellOlds, 2011; Vitousek, Mooney, Lubchenco, \& Melillo, 1997; Tilman and Lehman, 2001;). Coping with these conditions is, therefore, one of the main challenges faced by organisms throughout their lifespan. The sessile nature of plants makes this task even more demanding, as it requires the ability to respond without moving. Failure to do so would compromise their survival and reproduction, and increase the probability of population extinction (Willi \& Hoffmann, 2009).

Exposure to heavy metals (i.e. elements with a specific density $>5 \mathrm{~g} / \mathrm{cm}^{3}$; Jarup, 2003) is a powerful selective pressure for plants with important ecological and evolutionary implications (Antonovics, Bradshaw, \& Turner, 1971; Ernst, 2006; Macnair, 1987; Shaw, 1990; Boyd, 2004; Wright, Stanton, \& Scherson, 2006). Some heavy metals are essential for normal functioning in all plants but they can be toxic at high concentrations (e.g. $\mathrm{Co}, \mathrm{Cu}, \mathrm{Fe}, \mathrm{Mn}, \mathrm{Zn}$ ), while others have no known physiological functions and can be toxic even at very low concentrations (e.g. $\mathrm{Cd}, \mathrm{Pb}, \mathrm{Hg}$ ). Such toxicity can exert intense selective pressures on plants, and has led to the evolution of tolerant and/or hyperaccumulator ecotypes in many plant species (e.g. Pauwels, Frerot, Bonnin, \& Saumitou-Laprade, 2006; Reeves et al., 2017; Wright et al., 2006). The natural weathering of metal-rich rocks has generated soils to which some plant species have adapted in the long run, giving rise to a metallophyte flora with a considerable level of endemicity (e.g. Brooks and Malaisse, 1985; Kruckeberg and Kruckeberg, 1990; Reeves, Baker, Borhidi, \& Berazaín, 1996) of significant conservation value (Whiting et al., 2004). However, during the last decades anthropogenic activities have caused a dramatic increase in the concentrations of metals in soils that are not naturally enriched in metals as a result of surface deposition of dust and particles derived from industrial, agricultural, and mining activities, as well as energy production (Bradl et al., 2002; He, Yang, \& Stoffella, 2005; Singh, Labana S., Pandey, Budhiraja \& Jain, 2003). Such rapid increase in soil toxicity requires a similarly rapid response of plant populations to develop tolerance to heavy metal pollution, or the capacity to maintain fitness in the presence of exposure to heavy metals (Simms, 2000).

Most plants living in heavy metal enriched substrates have mechanisms to avoid uptake of metals while others can accumulate them at different levels (Adlassnig et al., 2016; Baker, 1981,). Accumulation and tolerance are thus complex genetically distinct quantitative traits that show high levels of inter- and intraspecific variation in plants (Goolsby and Mason, 2015). However, our current knowledge of the extent of intraspecific variation for heavy metal accumulation and tolerance in plants, the mechanisms underlying these traits, and their ecological and evolutionary significance is largely derived from tracheophytes, especially angiosperms (Cappa \& Pilon-Smits, 2014; Ernst, 2006; Reeves et al., 2017; Verbruggen, Hermans, \& Schat, 2009). Bryophytes have also shown the capacity to tolerate and accumulate high concentrations of these pollutants (Shaw, 1994). These plants diverged from their sister group of vascular plants $\sim 500$ mya, and they are non-vascular, gametophyte-dominant (haploid) plants with a relatively low degree of morphological and anatomical complexity, and a low capacity of self-internal regulation due to their poikilohydric nature (Vanderpoorten \& Goffinet, 2009). Since they use a variety of unique metabolic pathways to deal with environmental challenges (Cuming 2009; Glime, 2017a,b), their study could provide important insights into the evolution of these responses.

Several studies of inter- and intraspecific variation in the capacity of bryophytes to tolerate heavy metal pollution have found ecotypic differentiation, as well as broad inherent plasticity in a few species (e.g. Briggs, 1972; Brown \& House, 1978; Cogolludo, Estébanez, \& Medina, 2017; Jules \& Shaw, 1994; Shaw, 1988; Shaw, Antonovics, \& Anderson, 1987; Shaw, Jules, \& Beer, 1991). However, the bulk of the work on heavy metal tolerance and accumulation in natural bryophyte populations dates from the late 1970s and early 1990s, and was focused on a few target species. Recent research in this field has mostly focused on the applied value of bryophytes as biomonitors of heavy metal pollution (reviewed in: Ares et al., 2014; Fernández, Boquete, Carballeira, \& Aboal, 2015; Onianwa, 2001; Stanković, Sabovljević, \& Sabovljević, 2018) and phytoremediation (e.g. Itouga et al., 2017; Kobayashi, Kofuji R., Yamashita, \& Nakamura, 2006; Sandhi, Landberg, \& Greger, 2018; Sut-Lohmanna, Jonczakb, \& Raaba, 2020), or their physiological and biochemical responses to heavy metal exposure under controlled laboratory conditions without a clear focus 
on the natural variation of these traits (e.g. Bellini et al., 2020; Esposito et al., 2018; Kovácik, Dresler, \& Babula, 2020; Liang et al., 2018).

This study builds on the classic research to explore in more detail the extent of intraspecific phenotypic variation for heavy metal accumulation and tolerance in bryophytes in relation to contrasting habitat specialization. We selected two ecologically different terrestrial moss species with contrasting affinities for heavy metals, grew them in the laboratory under different metal treatments, and examined their patterns of accumulation and tolerance. Here, we define tolerance as the ability to maintain vegetative growth in a metal stressed vs. a control environment (sensu Simms, 2020). For the heavy metal specialist Scopelophila cataractae (Mitt.) Broth (Pottiaceae), we studied four field populations collected within a former copper mine to determine if there was variation for accumulation and tolerance among populations growing in a range of metal-rich soils. For the non-specialist, but metal tolerant Ceratodon purpureus (Hedw.) Brid. (Ditrichaceae), we studied one population collected in the field and compared it with male and female populations grown in the laboratory under axenic conditions. We evaluated phenotypic differences among populations, and examined whether sexes differed in their capacity to accumulate and tolerate metals, an aspect that has not been addressed previously to our knowledge. We predict that the metal specialist $S$. cataractae would show a "stress tolerator" strategy i.e. increased tolerance under similar accumulation levels, whereas the non-specialist C. purpureus would show a "stress avoidance" strategy, i.e. increased tolerance resulting from decreased accumulation, (sensu Baker, 1981). Also, we predict that females of C. purpureus would be more tolerant to heavy metal exposure than males as shown for other species in different environmental settings (Bowker, Stark, McLetchie, \& Mishler, 2000; Marks, Burton, \& Mcletchie, 2016; Moore, 2017).

\section{Material and Methods}

\subsection{Study species and field sampling.}

Scopelophila cataractae is one of the so-called "copper mosses" due to its high affinity for heavy metal enriched habitats (Shaw, 1993a). It is a Cu hyperaccumulator and $\mathrm{Cu}$ can reach up to $3 \%$ of the plant's dry weight (Aikawa, Nagano, Sakamoto, Nishiyama, \& Matsumoto, 1999; Nakajima, Itoh, Otake, \& Fujimoto, 2011; Satake, Shibata, Nishikawa, \& Fuwa, 1988). Similar to other copper mosses, S. cataractae has a broad but disjunct geographical distribution worldwide that roughly matches the distribution of copperenriched substrates (Shaw, 1987, 1993a,b, 1995). The species is dioecious, i.e. male and female gametangia are developed in different gametophores. Sporophytes, which are the diploid phase of the life cycle resulting from sexual reproduction, have never been observed in the populations used in this study suggesting that these populations are exclusively or mainly clonal.

Ceratodon purpureus is one of the most cosmopolitan bryophyte species with a broad ecological range. It occurs on a variety of substrates, ranging from well preserved to highly disturbed areas. Ceratodon purpureus also has separate sexes and it frequently undergoes sexual reproduction in unpolluted areas (Shaw et al., 1991). This species could thus be considered a pseudometallophyte or facultative metallophyte sensu Baker (1987).

In September 2016, we collected plants from four populations of S. cataractae in a mine site in Silver Hill, North Carolina (USA), whose activity was discontinued in the 1950s (Wickland 1984; Shaw, 1987). Here we use the term population to refer to physically unconnected and scattered patches of this species (separated by mostly bare soil), even though the distance between these patches was short ( $\sim 20$ to $\sim 300 \mathrm{~m})$. The mine was situated on a slope and populations were sampled down the slope beginning in the SE edge (Sc1), through the center of the mine (Sc2 and Sc3), and finishing in the NW edge (Sc4). On the same date, Ceratodon purpureus ( $\mathrm{Cp} 1$ ) was collected within an urban area in Durham, North Carolina (USA). At every site and sampling occasion, we used a knife to separate several clumps of moss from the soil. Various aliquots of gametophytic tissue from these clumps were stored in $1.5 \mathrm{ml}$ Eppendorf tubes and frozen in liquid nitrogen. The remaining material was put into zip-lock plastic bags and stored inside a cooler in the dark. In the laboratory, frozen samples were stored at $-80^{\circ} \mathrm{C}$ for microscopy analysis (section 2.5.2), an aliquot of fresh material was separated and dried to determine total $\mathrm{Cd}$ and $\mathrm{Cu}$ contents (section 2.5), another aliquot was 
separated to phenotype the plants (section 2.4.1), and the remaining material was maintained in a growth chamber at $22{ }^{\circ} \mathrm{C}$ and $16 \mathrm{~h} \mathrm{light} / 8 \mathrm{~h}$ dark to perform the common garden experiments. These conditions were maintained throughout the duration of the experiments.

Because mosses have no real roots, they are mostly influenced by the chemical composition of the surface soil layer. Thus, at each site we collected soil samples consisting of the upper 2-5 cm of soil right underneath the moss clumps to assess the levels of heavy metals to which mosses were exposed in their origin environments. These samples were stored in zip-lock plastic bags and kept in a cooler in the dark until further processing.

\subsection{Culture in the laboratory}

Before the treatments, we propagated all field populations of $S$. cataractae and $C$. purpureus in a growth chamber for several months to eliminate the physiological stress history of the plants, i.e. carryover of environmental effects. We carefully cleaned gametophytic tissue of $S$. cataractae under the dissection microscope using deionized (DI) water and a brush, cut it with a razor blade, and spread each population into $4 \times 4 \mathrm{~cm}$ pots containing a 2:1 mixture of clay (Turface) and commercial soil.

For C. purpureus, we sterilized gametophytic tissue of the field collected population, Cp1, using $0.2-1 \%$ bleach with shaking for 1-2 min, rinsing the tissue in sterile water with shaking for 1 minute, and spreading it into $9 \mathrm{~cm}$ petri dishes containing $30 \mathrm{ml}$ of BCD growth medium solidified with agar (Cove et al., 2009). Under the same conditions, we propagated one additional population of $C$. purpureus split into male and female plants growing separately (Cp2.m and Cp2.f respectively), donated by Dr. Stuart McDaniel from the University of Florida (Gainesville, USA).

\subsection{Heavy metal treatments}

The concentrations of $\mathrm{Cd}\left(\mathrm{as} \mathrm{CdCl}_{2}\right)$ and $\mathrm{Cu}\left(\mathrm{as} \mathrm{CuCl}_{2}\right)$ used in this study were selected to induce significant effects in moss performance without causing its death, according to the available literature (e.g. Ares, Itouga, Kato, \& Sakakibara, 2018; Carginale et al., 2004; Konno, Nakashima, \& Katoh, 2010), and culturing trials carried out in our laboratory.

For S. cataractae, we cut approximately 50-70 clean gametophores from each population into small pieces with a razor blade, mixed each with $2 \mathrm{ml}$ of DI water, and spread them in $4 \mathrm{x} 4 \mathrm{~cm}$ pots containing a previously autoclaved 2:1 mixture of clay (Turface) and potting soil. We cultured a total of 60 pots (4 populations x 3 treatments $\mathrm{x} 5$ replicates per population and treatment) for 3 months in the growth chamber, and watered the pots every two days with DI water. We applied the following treatments by watering the plants every two days for exactly 30 days with $20 \mathrm{ml}$ of: water (control), $1 \mathrm{mM} \mathrm{Cu}(\mathrm{Cu})$, and $0.1 \mathrm{mM} \mathrm{Cd}(\mathrm{Cd})(\mathrm{n}=4-5$ replicates per population in each of 3 treatments).

For C. purpureus, we transplanted 7-day old protonema into new petri dishes overlaid with sterilized cellophane discs. Each plate contained BCD medium enriched with metals under the following treatments: control $(\mathrm{C}), 0.02 \mathrm{mM} \mathrm{Cu}(\mathrm{Cu}), 0.01 \mathrm{mM} \mathrm{Cd}(\mathrm{Cd})(\mathrm{n}=7$ replicates per population and treatment). The levels of $\mathrm{Cd}$ and $\mathrm{Cu}$ in the treatments differed between species due to their obvious differences in tolerance. The treatment lasted 21 days and we took pictures of each replicate at the beginning and at the end of the experiment to measure the individual growth of each protonemal mat ( $\mathrm{n}=5$ mats per replicate).

In both experiments, we changed the position of the replicates within the chamber every week to minimize local microenvironmental effects. At the end of each common garden experiment, we harvested the plants, blotted them with filter paper, and separated several aliquots from each population and treatment in order to perform different analyses: several aliquots were immediately frozen in liquid $\mathrm{N}$ and stored at $-80^{\circ} \mathrm{C}$ for lipid peroxidation and microscopy analyses; one aliquot was kept in the oven at $50{ }^{\circ} \mathrm{C}$ in plastic tubes for total $\mathrm{Cd}$ and $\mathrm{Cu}$ determination; one last aliquot was stored at $4^{\circ} \mathrm{C}$ in the fridge to phenotype the plants (only in S. cataractae).

\subsection{Measurements of plant performance}

2.4.1 Growth of C. purpureus and morphology of S. cataractae 
We measured plant vegetative growth as a proxy for fitness. For $S$. cataractae, we measured the following morphological traits in 10 gametophores from each population and treatment: i) plant length, as the length in $\mathrm{mm}$ of the green part of the gametophyte; ii) leaf length, as the average length in $\mathrm{mm}$ of three leaves per shoot from the apical most part of the gametophore; and iii) leaf width, as the average width in $\mathrm{mm}$ of the same three leaves. These same traits were also measured in 50 gametophores from each field population of S. cataractae .

Because the area of the protonemal mat is considered a suitable proxy for biomass production in mosses (Burtscher, List, Payton, McDaniel, \& Carey, 2020), for C. purpureus we calculated total growth by subtracting the area of each protonemal mat $\left(\mathrm{mm}^{2}\right)$ at the beginning of the experiment to the area at the end of the experiment, and averaged the growth of 5 mats for each replicate.

All morphological and growth measurements were made by processing the photos taken of $S$. cataractae and C. purpureus with ImageJ v1.51 (Schneider, Rasband, \& Eliceiri, 2012).

\subsubsection{Lipid peroxidation}

We evaluated lipid peroxidation of the plasma membrane as a proxy of the level of oxidative damage in plant tissues grown under the different treatments ( $n=3$ replicates per sample) by measuring the amount of malondialdehyde (MDA) following the thiobarbituric acid (TBA) assay described by Heath \& Packer (1968) and Catalá et al. (2010). We first prepared a $2 \mathrm{mM}$ stock solution of the MDA precursor, malonaldehyde bis(diethyl acetal) (1,1,3,3-Tetraethoxypropane; Sigma Aldrich, T9889) and built standards of 0, 5, 10, 20, and $40 \mu \mathrm{M}$ MDA by diluting the stock solution in $80 \%$ ethanol with $2 \%$ buthylated hydroytholuene (BHT; Fisher Scientific, ICN10116290). For each sample, we homogenized between 3.6 and $75.8 \mathrm{mg}$ of frozen moss tissue in a tissue lyser (Qiagen TissueLyser II) during 2-4 min, in rounds of $30 \mathrm{sec}$. Samples were immersed in liquid $\mathrm{N}$ between rounds to prevent tissue melting. We then added $1 \mathrm{ml}$ of $0.1 \%$ trichloroacetic acid (TCA; Fisher Scientific, ICN19605780) to each sample and standard, and vortexed them. We centrifuged all tubes at 10,000 g for 20 minutes and recovered $500 \mu \mathrm{l}$ of supernatant. We added an equal volume of $20 \%$ TCA containing $0.5 \%$ TBA (Sigma Aldrich, T5500-25G) to each tube, followed by $5 \mu$ l of BHT. All tubes were incubated at $95^{\circ} \mathrm{C}$ in a hot plate for 30 minutes, cooled quickly on ice, and centrifuged at 10,000 $\mathrm{g}$ for $15 \mathrm{~min}$. Finally, we recovered the supernatant, and measured its absorbance at 532 and $600 \mathrm{~nm}$ in a 96-well spectrophotometric microplate reader (Epoch Biotek). The concentration of MDA was calculated after subtracting the absorbance at $600 \mathrm{~nm}$ from that at $532 \mathrm{~nm}$ to eliminate the possible interference of soluble sugars present in the samples (Du \& Bramlage, 1992).

\subsection{Contents of heavy metals}

\subsubsection{Total Cd and Cu content in moss and soil}

We dried moss tissue from all populations and treatments at $50{ }^{\circ} \mathrm{C}$, including field samples, and ground them to a fine powder in a tissue lyser ( $\mathrm{n}=3$ replicates per sample). Then, we digested between 1-17 mg of plant tissue in small Teflon vessels with $2 \mathrm{ml}$ of $\mathrm{HNO}_{3}(100 \%$, TraceMetal Grade, Fisher Chemical) in a hot plate at $175^{\circ} \mathrm{C}$. After $2 \mathrm{~h}$, we added $0.8 \mathrm{ml}$ of $\mathrm{H}_{2} \mathrm{O}_{2}$ (ACS grade) to each sample and incubated them again for $2 \mathrm{~h}$ at $175^{\circ} \mathrm{C}$. We also prepared one sample of certified reference material (M2,Pleurozium schreberi moss tissue, Steinnes, Ruhling, Lippo, \& Makinen, 1997) in the same way, and analyzed it along with analytical blanks after every 12 samples to control for instrumental precision and contamination.

Similarly, we dried soil samples from the field ( $\mathrm{n}=3$ replicates per sample), sieved them to separate the $2 \mathrm{~mm}$ fraction, and ground them to a fine powder before analysis. Between 9-30 $\mathrm{mg}$ of dried soil were digested in small Teflon vessels with $2 \mathrm{ml}$ of $\mathrm{HNO}_{3}(100 \%)$ for $8 \mathrm{~h}$ at $175^{\circ} \mathrm{C}$. This acid dissolves only a very small fraction of structural minerals in the soil recovering mainly the most labile/reactive fraction of heavy metals (Melo, Batista, Gilkes, \& Rate, 2016). We used one certified reference material prepared in the same way as the samples, once every 12 samples, to control for instrumental precision (marine sediment PACS-2, National Research Council of Canada).

Total contents of $\mathrm{Cd}$ and $\mathrm{Cu}$ were determined in both matrices at the College of Marine Sciences (Univer- 
sity of South Florida) by Inductively Coupled Plasma Mass Spectrometry (ICP-MS, Agilent 7500cx). The percentage recovery averaged $82 \%$ and $86 \%$ for $\mathrm{Cu}$ in plant and soil respectively, and $102 \%$ and $131 \%$ for $\mathrm{Cd}$ in plant and soil respectively.

\subsubsection{Relative $C d$ and $C u$ content in moss}

We mounted freeze-dried samples from each population and treatment on aluminum stubs with double sticky carbon disks (SEM-carbon foils, PELCO Tabs ${ }^{\mathrm{TM}}$ Carbon Conductive Tabs, Double Coated) and then carbon coated them with a 10-20 nm carbon layer (Leica EM MED 020) to prevent surface charge. We carried out all measurements with scanning electron microscope JEOL JSM-IT300 (SEM) in combination with energy dispersive X-ray microanalysis (EDX) for elemental analyses by SDD (silicon drift detector) and software TEAM V.4.3, operating at $20 \mathrm{kV}$. We used the following acquisition conditions: $35^{\circ}$ take off angle, a $30 \mathrm{~s} \mathrm{live}$ time, and a $30 \%$ dead time. For S. cataractae, we selected 6 plants per population and treatment (including field samples, in which only the leaves could be measured), and performed 4 measurements per plant: two on two different leaves, and two on the stem ( $n=12$ measurements for each of the structures, except for $\mathrm{Sc} 1$ in which $\mathrm{n}=6$ for stems). For $C$. purpureus protonema, we performed a total of $\mathrm{n}=10$ measurements per population and treatment. Relative concentrations are expressed as weight percent (i.e. weight of the element of interest divided by the weight of all elements present in the sample).

\subsection{Statistical analyses}

We used generalized linear models ( $g l m$ function within R v.3.5.1, R Core Team, 2018, running under R Studio v.1.2.5019, RStudio Team, 2019) to evaluate the effect of population (4 levels) on the variables measured in the field-collected samples of $S$. cataractae, and the effects of population (3 levels for C. purpureus ; 4 levels for $S$. cataractae ), treatment ( 2 levels: control vs $\mathrm{Cd}$; control vs $\mathrm{Cu}$ ) and their interaction on the variables measured in both species during the common garden experiments using the gamma distribution with the $\log$ link function in most cases (but see Table 1 for more details). The field samples and the four common garden experiments comprised the following datasets: i) Field samples: total concentrations of Cd and $\mathrm{Cu}$ in soil; total and relative concentrations of $\mathrm{Cd}$ and $\mathrm{Cu}$, and plant length, leaf length, and leaf width in $S$. cataractae ; ii) Common garden: total and relative concentrations of $\mathrm{Cd}$ and $\mathrm{Cu}$, and concentration of MDA in S. cataractae and C. purpureus ; protonemal growth in C. purpureus, and plant length, leaf length, and leaf width in $S$. cataractae. In the common garden, we compared the responses to each of the specific treatments ( $\mathrm{Cd}$ enriched and $\mathrm{Cu}$ enriched) to the control conditions for each species.

We graphically inspected residuals of the models for any trends, and tested for normality and homoscedasticity using the functionsshapiro.test and leveneTest respectively. When these assumptions were not met, we tried other family distributions to model the response (inverse gaussian with log link, and gaussian with inverse link), used standardized variables (mean $=0$, standard deviation $=1$ ), or applied BoxCox transformations (Box \& Cox, 1964) in order to improve the fit of the models (summarized in Table 1). Then we used the functionanova to test for the significance of the main effects of the models followed by multiple pairwise comparisons using the functionglht (multcomp package, Hothorn, Bretz, \& Westfall, 2008) when the main effects were significant. Finally, all p-values were adjusted using the Benjamini \& Hochberg (1995) method to obtain false discovery rates (FDR).

We used a Kruskal Wallis test to assess the effect of the treatment on the total concentrations of Cd and $\mathrm{Cu}$ in C. purpureus in the laboratory without accounting for the population effect due to the low number of replicates.

\section{Results}

\subsection{Heavy metal levels and morphology of S. cataractae from the field}

The concentrations of $\mathrm{Cd}$ and $\mathrm{Cu}$ in soils (total levels) differed significantly across sites $\left(\chi^{2}=0.64, \mathrm{p}<2.2 \mathrm{e}^{-16}\right.$ and $\chi^{2}=4.36, \mathrm{p}<2.2 \mathrm{e}^{-16}$ for $\mathrm{Cd}$ and $\mathrm{Cu}$ respectively; Figure 1 ). Site 2 (in the center of the mine) showed the highest concentrations of $\mathrm{Cu}$, followed by sites 1 (edge) and 3 (center), and ultimately 4 (edge). For Cd, site 3 showed the highest concentration followed by sites 2, 1 and 4 (which did not differ from each other). 
Total levels of $\mathrm{Cd}$ and $\mathrm{Cu}$ inS. cataractae also differed among populations $\left(\chi^{2}=3.00, \mathrm{p}<0.0001\right.$ and $\chi^{2}=$ $1.28, \mathrm{p}<0.001$ for $\mathrm{Cd}$ and $\mathrm{Cu}$ respectively), however, the differences found in plants did not reflect the same pattern as found in soils. Total and relative $\mathrm{Cu}$ were highest in Sc3 and did not differ significantly among the other three populations (Fig. 1B and 1C). Total Cd was lowest in Sc1 and did not differ significantly among the other three populations (Fig. 1D). The relative levels of $\mathrm{Cd}$ in plant tissue, however, did not show significant differences among populations $\left(\chi^{2}=0.02, p=0.615\right.$; Fig. $\left.1 F\right)$.

The morphological measurements performed on the field samples revealed that plants from the center of the mine (Sc2, Sc3) were smaller than those from the edges (Sc1, Sc4) for all traits studied except leaf width in Sc2 $\left(\chi^{2}=24.80, \mathrm{p}<2.2 \mathrm{e}^{-16}\right.$ for plant length; $\chi^{2}=2.75, \mathrm{p}<2.2 \mathrm{e}^{-16}$ for leaf length; $\chi^{2}=3.39, \mathrm{p}<2.2 \mathrm{e}^{-16}$ for leaf width; Fig. $1 \mathrm{G}$ to I).

\subsection{Heavy metal uptake and tolerance in S. cataractae: common garden experiment}

Total and relative concentrations of $\mathrm{Cd}$ and $\mathrm{Cu}$ increased substantially in all treated plants compared to controls as shown in Figure $2\left(\chi^{2}\right.$ treatment $=4.57$ for total $\mathrm{Cd} ; \chi^{2}$ treatment $=143.07$ for total $\mathrm{Cu} ; \chi^{2}$ treatment $=40.88$ for relative $\mathrm{Cd}$ in leaves; $\chi^{2}$ treatment $=28.89$ for relative $\mathrm{Cd}$ in stem; $\chi^{2}$ treatment $=52.15$ for relative $\mathrm{Cu}$ in leaves; $\chi^{2}$ treatment $=102.36$ for relative $\mathrm{Cu}$ in stem; $\mathrm{p}<2.2 \mathrm{e}^{-16}$ in all cases). For $\mathrm{Cu}$, all populations reached similar total concentrations as well as similar relative levels of $\mathrm{Cu}$ on the stems at the end of the experiment (Fig. 2A and C), except for treated Sc4 that accumulated significantly more $\mathrm{Cu}$ in the stems than the other populations. The magnitude of the treatment effect, however, differed among populations for the relative levels of $\mathrm{Cu}$ in leaves as indicated by the significant "Population by Treatment" interaction $\left(\chi^{2}\right.$ pop:treat $\left.=8.61, \mathrm{p}<0.0001\right)$. In particular, populations Sc1 and Sc4, from the edges of the mine, showed higher relative levels of $\mathrm{Cu}$ in leaves after treatment than $\mathrm{Sc} 2$ and Sc3, from the center $(\mathrm{z}=-6.82$ for Sc1 vs $\mathrm{Sc} 2 ; \mathrm{z}=-6.81$ for $\mathrm{Sc} 1$ vs Sc3, 5.45 for $\mathrm{Sc} 4$ vs Sc2, 5.51 for $\mathrm{Sc} 4$ vs Sc3; $\mathrm{p}<0.0001$ in all cases). We also found that the levels of $\mathrm{Cu}$ in the stems exceeded those in the leaves in Sc2, Sc3, and Sc4 $(\mathrm{z}=5.23, \mathrm{p}<0.0001$ for Sc2; $\mathrm{z}=5.31, \mathrm{p}<0.0001$ for Sc3; $\mathrm{z}=2.50, \mathrm{p}<0.05$ for Sc4) but not in Sc1 ( $\mathrm{z}=-1.09, \mathrm{p}=0.405)$.

For Cd, Sc3 and Sc4 reached significantly higher total concentrations than Sc1 and Sc2 (Fig. 2D), and the relative levels in leaves showed a similar pattern, except that Sc3 did not differ significantly from Sc2 and Sc4 (Fig. 2E). All four populations reached similar relative levels of $\mathrm{Cd}$ in the stems. Finally, contrary to what we found for $\mathrm{Cu}$, the levels of $\mathrm{Cd}$ in the leaves exceeded those in stems only for Sc4 $(\mathrm{z}=-4.384, \mathrm{p}<0.001)$, and they did not differ among the other three populations.

Generalized linear models on growth revealed a significant "Population by Treatment" interaction in the effect of $\mathrm{Cu}$ in plant length, leaf length and leaf width $\left(\chi^{2}\right.$ pop:treat $=0.80, \mathrm{p}<0.05$ for plant length; $\chi^{2}$ pop:treat $=0.57, \mathrm{p}<0.01$ for leaf length; and $\chi^{2}$ pop:treat $=0.37, \mathrm{p}<0.05$ for leaf width). For $\mathrm{Cd}$, this interaction was only significant for the length of the leaves $\left(\chi^{2}\right.$ pop:treat $\left.=0.49, \mathrm{p}<0.05\right)$. In general, gametophores from Sc2 were smaller than those from all other populations when grown in control conditions. Both metals seem to enhance Sc2 growth, as shown by the tendency towards higher means in all traits in treated plants compared to controls (means increased by 50,14,11\% in Cu-treated plants for plant length, leaf length and leaf width respectively, and by 2,14 , and $11 \%$ in Cd-treated plants for plant length, leaf length and leaf width respectively), although the differences were statistically significant only for plant length between control and $\mathrm{Cu}$-treated $(\mathrm{z}=2.88, \mathrm{p}<0.05)$. Populations $\mathrm{Sc} 1$ and Sc4 showed the opposite trend, with generally higher trait means in controls than in treated plants. Tests yielded significant differences for plant length between control and Cd-treated $(\mathrm{z}=-2.47, \mathrm{p}<0.05$; Fig. 3E), and leaf length and leaf width between control and $\mathrm{Cu}$-treated in $\mathrm{Sc1}(\mathrm{z}=-3.36, \mathrm{p}<0.01$ and $\mathrm{z}=-2.94, \mathrm{p}<0.05$ respectively; Fig. 3B,C), and for leaf length between control and $\mathrm{Cd}-$ and $\mathrm{Cu}$-treated plants in $\mathrm{Sc} 4(\mathrm{z}=-3.01, \mathrm{p}<0.05$ and $\mathrm{z}=-2.79, \mathrm{p}<0.05$ respectively; Fig. 3B,F). Treatments did not significantly affect Sc3 and, overall, trait means of control and treated plants are pretty close.

Finally, $\mathrm{Cu}$ caused a significant and consistent increase in the concentrations of MDA in all populations $\left(\chi_{\text {treatment }}^{2}=0.35, \mathrm{p}<2.2 \mathrm{e}^{-16}\right.$; Fig. 3D $)$ that averaged overall $14.2 \mu \mathrm{M}$ in control cultures and $80.5 \mu \mathrm{M}$ in $\mathrm{Cu}$-enriched media. This effect was not significant for $\mathrm{Cd}$-enriched cultures that exhibited mild and 
non-consistent changes in MDA concentrations (Fig. 3H).

\subsection{Heavy metal uptake and tolerance in C. purpureus: common garden experiment}

The total concentrations of $\mathrm{Cd}$ and $\mathrm{Cu}$ in the soil where we collected $\mathrm{Cp} 1$ were $0.39 \pm 0.07$ and $15.9 \pm 4.7$ $\mu \mathrm{g} \mathrm{g}{ }^{-1}$ respectively. Total concentrations of $\mathrm{Cd}$ and $\mathrm{Cu}$ increased significantly in $\mathrm{Cd}$ - and $\mathrm{Cu}$-treated plants $\left(\chi_{\text {treatment }}^{2}=7.5, \mathrm{p}<0.01\right.$ for $\mathrm{Cd} ; \chi^{2}$ treatment $=8.31, \mathrm{p}<0.01$ for $\mathrm{Cu} ;$ Fig. $\left.4 \mathrm{~A}, \mathrm{E}\right)$. The relative levels of both metals increased significantly in almost all populations as indicated by the significant effect of the treatment $\left(\chi_{\text {treatment }}^{2}=2.06, \mathrm{p}<0.001\right.$ for $\mathrm{Cu} ; \chi^{2}$ treatment $=6.88, \mathrm{p}<0.0001$ for $\mathrm{Cd}$; Fig. $\left.4 \mathrm{~B}, \mathrm{~F}\right)$. The "Population by Treatment" interaction was significant only for $\mathrm{Cu}\left(\chi^{2}\right.$ pop:treat $\left.=1.07, \mathrm{p}<0.05\right)$ as $\mathrm{Cu}$-treated plants did not accumulate more $\mathrm{Cu}$ than control plants for $\mathrm{Cp} 1$. Exposure to these metals caused a significant decrease in protonemal growth in all three populations $\left(\chi^{2}\right.$ treatment $=2.31, \mathrm{p}<0.0001 \mathrm{for} \mathrm{Cu} ; \chi^{2}$ treatment $=98.50, \mathrm{p}$ $<2.2 \mathrm{e}^{-16}$ for Cd; Fig. 4C, G) although the magnitude of the effect differed among populations as indicated by the significant "Population by Treatment" interaction $\left(\chi^{2}\right.$ pop:treat $=33.20, \mathrm{p}<0.0001$ for $\mathrm{Cu} ; \chi^{2}$ pop:treat $=8.21, \mathrm{p}<0.0001$ for $\mathrm{Cd}$ ). Thus, whereas the mean size of the protonemal mat of $\mathrm{Cu}$-treated plants of $\mathrm{Cp} 1$ decreased by $17 \%$, it decreased by 47 and $59 \%$ in Cp2.m and Cp2.f respectively. For Cd, the mean size of the protonemal mats decreased by 53, 74 and $26 \%$ in Cd-treated plants from Cp1, Cp2.m and Cp2.f respectively.

$\mathrm{Cu}$ treatment did not have a significant effect in oxidative damage as measured by the concentrations of MDA. However, Cd treatment showed a significant effect and this effect differed across populations $\left(\chi^{2}\right.$ pop:treat $=$ $3.60, \mathrm{p}<0.0001)$ with males from $\mathrm{Cp} 2(\mathrm{Cp} 2 . \mathrm{m})$ experiencing more damage than $\mathrm{Cp} 1$ and females from the same population (Cp2.f).

\section{Discussion}

Human activities are profoundly reshaping the Earth to the point that scientists proposed to define a new geological epoch, the Anthropocene (Lewis \& Maslin, 2015). The continuous global emission of highly toxic pollutants taking place during this epoch (Vallack \& Rypdal, 2019), challenges the capacity of plants to respond to the rapid shifts in environmental conditions. Organisms can accommodate to challenging environmental conditions through phenotypic plasticity (Bradshaw, 2006; Nicotra et al., 2010), i.e. the ability of a single genotype to express different phenotypes under diverse environmental conditions (Bradshaw 1965, 2006; Kelly, Panhuis, \& Stoehr, 2012; Schlichting, 1986; Sultan, 1987, 2000). Indeed, a now classic expectation is that plasticity of functional traits may contribute to the survival of plants in highly heterogeneous environments and changing environmental conditions (e.g. Henn et al., 2018; Lázaro-Nogal et al., 2015; McIntyre \& Strauss, 2014; Richards et al. 2010;), particularly in clonal plants or during the invasion of new habitats where genetic diversity can be limited (e.g. Drenovsky et al., 2012; Geng et al. 2007; Richards, Bossdorf, Muth, Gurevitch, \& Pigliucci, 2006; Richards et al., 2008; Turner, Fréville, \& Rieseberg, 2015; Williams, Mack, \& Black, 1995). Hence, plasticity could be a critical component of population and, ultimately, species persistence under the current context of global change (Nicotra et al. 2010; Parmesan \& Hanley 2015).

In order to understand whether phenotypic plasticity contributes to individual, population and/or species survival, we need to better understand the levels of phenotypic variation in response to specific environmental drivers in different plant taxa (Arnold, Kruuk, \& Nicotra, 2019; Nicotra et al. 2010; Parmesan \& Hanley 2015). In this context, we investigate the patterns of intraspecific variation for heavy metal accumulation and tolerance in two bryophyte species with contrasting affinity for heavy metals and discuss the mechanistic basis for such differences. The present investigation adds to current knowledge on the extent and patterns of phenotypic variation in a group of plants highly tolerant to environmental stress but whose response mechanisms are relatively understudied.

\subsection{The heavy metal specialist: Scopelophila cataractae}

The unique ecological specialization of $S$. cataractae for heavy metals has inspired some research on its phenotypic variation in the past. In studies across the broad and discontinuous geographical range of this species, Shaw (1993b, 1995) found high levels of morphological variation in several leaf and cell traits of the gametophores; most of this variation (up to $78 \%$ ) was found among individuals within populations, even 
though he included populations from five widely separated geographical regions (Shaw 1993b). Allozyme analyses on a subset of these populations showed high genetic variation at the species level that was mostly accounted for by variation among populations, and many populations were genetically uniform (Shaw, 1995). Some of these populations never showed evidence of sexual reproduction (by presence of sporophytes) and were mainly comprised of sterile plants and plants from only one sex (Shaw 1993a; 1995), suggesting that they were clones. Therefore, Shaw (1995) attributed the high levels of morphological variation within populations of $S$. cataractae to phenotypic plasticity rather than genetic variation.

Our field populations also consisted almost entirely of non-sexual plants (except for Sc3 where $20 \%$ of the plants bore male gametangia and $80 \%$ did not express sex) and no sporophytes were observed in this, or previous studies of these populations (e.g. Shaw, 1993a). Although we cannot rule out some genetic differentiation among our populations, we expected some gene flow among populations through the movement of asexual propagules (e.g. gemma) or fragments of gametophores from one population to the other populations (especially down the slope from Sc1 towards Sc4 passing through Sc2 and Sc3) due to their geographical proximity $(<500 \mathrm{~m}$ away from each other). Under these circumstances, we expected limited levels of phenotypic differentiation among our populations. Still, we demonstrated, for the first time, the existence of intraspecific differentiation for heavy metal accumulation and tolerance in S. cataractae on a very limited geographical scale. This finding suggests high phenotypic variation among populations with potentially limited genetic diversity.

The differences that we found for this species contrast to some extent with the results of previous experimental work on S. cataractae. Shaw $(1987,1993 a)$ propagated gametophytic tissue of eight and five North American populations of this species respectively growing under different levels of heavy metal pollution in the field on different soil-types: polluted soil (mine soil enriched in $\mathrm{Cu}$ and $\mathrm{Zn}$ ), unpolluted soil, and mixtures of these two. He found a strong effect of soil-type on plant growth, and all populations grew better in polluted than unpolluted soils in both studies. All populations performed equally well in polluted soil regardless of their original environment, but some populations grew better than others in control and mixed soils (Shaw, 1993a). In our study, populations responded differently to $\mathrm{Cd}$ and $\mathrm{Cu}$, and this response was related to the levels of metals in their origin environments, i.e. those exposed to higher levels of metals in the field were the most tolerant. This discrepancy could be explained partly by the differences in the way that the treatments were applied. We applied $\mathrm{Cd}$ and $\mathrm{Cu}$ in solution to a commercial soil, so both metals were readily and directly available for the plants, which was not true in the mine soil in Shaw's studies $(1987,1993 a)$. Because the amount of phenotypic variation expressed by one species can vary between environments (e.g. Pigliucci, 2001; Richards et al., 2006, 2010; Shaw 1993a), our experimental conditions could reveal novel differences in metal tolerance in $S$. cataractae, similar to how unpolluted and mixed soils revealed phenotypic differences that were not evident in polluted soil (Shaw 1993a) Interestingly, the phenotypic differentiation found in our study resulted after only 30 days of treatment of adult gametophores. We thus predict that differences among populations would be even greater if the treatments had been applied from the beginning of the experiment.

Aside from the metal treatments, plants from Sc2, collected from the site with an outstanding concentration of $\mathrm{Cu}$, were always smaller than plants from the other three populations when grown in the laboratory under control conditions. This pattern suggests that greater metal tolerance may come with a biological cost, at least in Sc2, a phenomenon previously reported for other bryophytes (Jules and Shaw, 1994). Metal tolerance entails a metabolic cost due to the allocation of energetic resources to counteracting the potentially toxic effect of metals (e.g. synthesis of chelating agents, upregulation of the ROS scavenging machinery, metal transportation; see Maestri, Marmiroli, Visioli, \& Marmiroli, 2010). Other adverse environmental conditions that characterize polluted soils, i.e. intense sun exposure, poor nutrient supply, or low water retention capacity, also contribute to the slower growth rates, lower biomass production, and lower reproductive output of metal-adapted plants (Baker, 1987; Bothe and Slomka, 2017; Ernst 2006). In this study, plants were sampled in microhabitats that clearly differed between the center and the edges of the mine. In particular, the center of the mine was devoid of any vegetation except for the mats of $S$. cataractae so plants from Sc2 and Sc3 surely experienced higher light and temperatures, and lower water availability. On the contrary, plants from Sc1 and Sc4 were under vascular plant cover and Sc4 was alongside a seasonal streamlet that had abundant 
water during sample collection. All these microhabitat differences, including their different metal levels (Fig. 1A, D), are reflected in the smaller size of plants from Sc2 and Sc3 in the field (Fig. 1G-I), and were maintained to some extent in $\mathrm{Sc} 2$ in the common garden experiment under control conditions, suggesting that this population maintained the "metal-tolerant phenotype" beyond the field.

All populations of $S$. cataractae in this study behaved as $\mathrm{Cd}$ - and $\mathrm{Cu}$-hyperaccumulators according to Maestri et al. (2010), as their total concentrations reached $1 \%$ d.w. of $\mathrm{Cu}(1.1 \%$ in Sc1 and Sc3, $0.96 \%$ in Sc2, and $1.0 \%$ in Sc4) and between $0.21-0.45 \%$ d.w. of $\mathrm{Cd}(0.21,0.19,0.30,0.45 \%$ in Sc1 to Sc4 respectively) (Fig. $2 \mathrm{~A}, \mathrm{D})$. Although we did not find differences in the total concentrations of $\mathrm{Cu}$ among populations, i.e. no differences in their capacity to accumulate $\mathrm{Cu}$, the relative concentrations in leaves of plants from central mine populations, Sc2 and Sc3, were lower than those in leaves of plants from the mine edges, Sc1 and Sc4. Also, relative levels of $\mathrm{Cu}$ in stems of Sc2, Sc3 and Sc4 exceeded those in leaves. Therefore, we speculate that relocation of absorbed $\mathrm{Cu}$ towards the stem could protect leaves and their photosynthetic activity and explain to some extent the higher tolerance observed in Sc2 and Sc3. Some studies have already shown evidence for acropetal and basipetal transport of elements, including metals, within moss gametophores (Brumelis \& Brown, 1997; Sidhu \& Brown, 1996; Wells \& Brown, 1996), as well as differences in preferential accumulation of $\mathrm{Cu}$ in specific parts of the gametophores between tolerant and non-tolerant moss species (Antreich, Sassmann, \& Lang, 2016). Moss leaves are important functional organs whose structure allows maximization of light and nutrient capture, and gas exchange, making them very efficient photosynthetic structures (Renzaglia, Duff, Nickrent, \& Garbary, 2000; Renzaglia et al., 2007). Thus, leaf protection seems a plausible explanation for the tissue-specific relative levels of $\mathrm{Cu}$ found here.

The high affinity of $S$. cataractae for $\mathrm{Cu}$ has been demonstrated by its repeated appearance in $\mathrm{Cu}$-enriched substrates worldwide (see Shaw, 1993b), experimentally by Shaw $(1987,1993 \mathrm{a})$ and more recently by Nomura \& Hasezawa (2011). Nomura \& Hasezawa (2011), however, showed that the beneficial effect of $\mathrm{Cu}$ on protonemal growth was reversed at $1 \mathrm{mM} \mathrm{CuSO}_{4}$. At this concentration, the size of the protonemal mats growing axenically in agar plates decreased slightly compared to the controls. Thus, even though this species constitutively needed high concentrations of $\mathrm{Cu}$ to perform at its best, too high concentrations such as those used in the present study and in Nomura \& Hasezawa (2011) may result in toxicity (e.g. increase in oxidative damage shown in Fig. 3D), and reveal differences in tolerance and accumulation patterns that would otherwise have been hidden. On the contrary, $\mathrm{Cd}$ is non-essential, highly toxic, and there is no evidence of $S$. cataractae showing high affinity for this metal which might explain the intraspecific differences observed in the capacity of $S$. cataractae to accumulate Cd (Fig. 2D) and the lack of preferential relocation towards the stem.

\subsection{The facultative metallophyte: Ceratodon purpureus}

Ceratodon purpureus has a wide geographical range (Crum \& Anderson, 1981) and occurrs in habitats with diverse environmental characteristics: acid to calcareous soils, sandy, woody, or rocky substrates with varying amounts of surrounding vegetation (from bare soil to well-developed canopies), and different degrees of disturbance (see Atherton, Bosanquet, Lawley, 2010; Dunham, 1951; Ireland, 1982; Shaw et al., 1991), suggesting that this moss species has a broad ecological tolerance. Previous studies on heavy metal tolerance in this species showed that $C$. purpureus harbored a constitutive capacity to tolerate and survive in heavy metal enriched environments (Shaw et al., 1991) but it can also undergo ecotypic differentiation when subjected to a strong enough selective pressure (Jules \& Shaw 1994). This study provides further support for the high resilience of this species by showing evidence of intraspecific differences in heavy metal tolerance between populations that had never experienced high levels of metals in the field.

Both $\mathrm{Cu}$ and $\mathrm{Cd}$ negatively affected negatively all populations from this study, but the magnitude of this effect on each population depended on the metal and on the trait measured. Protonemal growth was reduced on average by only $17 \%$ in $\mathrm{Cp} 1$ under $\mathrm{Cu}$ treatment, whereas this decline was 2.8 and 3.5 times higher in males and females from $\mathrm{Cp} 2$ respectively (Fig. 4C). One could argue that the higher $\mathrm{Cu}$ tolerance of $\mathrm{Cp} 1$ could be due to a general hardiness effect, as this was collected in the field where it likely experienced some stress which could translate to general stress tolerance, whereas $\mathrm{Cp} 2$ had been growing in the laboratory 
for several years. However, we do not think that this is the case for two reasons. First, plants of Cp1 were dehardened to a certain degree before the experiments by propagating several clonal generations in the laboratory. Second, if this were the case we would expect $\mathrm{Cp} 1$ to be more Cd tolerant as well, which we did not find. The female lab strain, Cp2.f, was more tolerant to $\mathrm{Cd}$ than individuals derived from the field collected plants, Cp1, and the male lab strain, Cp2.m, whose average growth dropped 2.0 and 2.9 times more respectively than in Cp2.f (Fig. 4G). Treatment with $\mathrm{Cu}$, did not cause a significant increase in MDA in any of the populations (Fig. 4D). However, there was an effect of $\mathrm{Cd}$ on the concentration of MDA in the plants which paralleled the pattern shown by the protonemal growth, suggesting females (Cp2.f) had less oxidative damage and were more Cd-tolerant than $\mathrm{Cp} 1$ and $\mathrm{Cp} 2 . \mathrm{m}$.

All populations of $C$. purpureus in this study reached the threshold concentrations for Cd hyperaccumulators, i.e. [?] $0.01 \%$ (Maestri et al., 2010), whereas total $\mathrm{Cu}$ concentrations were an order of magnitude below the threshold for $\mathrm{Cu}$ hyperaccumulators ([?] 0.1\%). Despite the significant increase in total and relative concentrations of $\mathrm{Cd}$ and $\mathrm{Cu}$ in all treated plants compared to their controls (except for relative $\mathrm{Cu}$ in Cp1), metal accumulation seemed to be similar in all populations indicating that the differences observed in tolerance were not related to differences in their capacity to take up metals. Thus, we hypothesize that the observed differences in tolerance could be due to two complementary mechanisms. First, bryophytes have a high cation exchange capacity (CEC) in their cell walls that plays a major role in nutrient and heavy metal uptake, binding, and regulation (Richter and Dainty, 1989), and depends on the composition of the cell wall. Further, the structure and composition of the cell wall of bryophytes can change in response to environmental cues such as heavy metal exposure (Konno et al., 2010; Krzeslowska, Lenartowska, Mellerowicz, Samardakiewicz, Wozny, 2009). Therefore, differences in the original composition of the wall, or in the way it responds to heavy metal exposure could explain the differences in its capacity to bind metals and prevent their entrance inside the cells, limiting their toxicity, while still being accounted for in our total and relative concentrations. Second, especially for Cd that caused a population-specific increase in oxidative damage (MDA), it is possible that the capacity of the ROS scavenging systems differed among our field and lab-reared populations, contributing to the observed differences in tolerance.

Finally, our results showed, for the first time, evidence for metal-dependent, sex-specific differences in heavy metal tolerance in bryophytes. Both sexes were similarly tolerant to $\mathrm{Cu}$ but females were significantly more tolerant to $\mathrm{Cd}$ than males, as evidenced by both protonemal growth and oxidative damage data. Dioecy has evolved multiple times in bryophytes, leading to more than $50 \%$ of the species having separate sexes (Bisang \& Hedenäs, 2005; McDaniel, Atwood, \& Burleigh, 2012). Sexual dimorphism in morphological, physiological, and life history traits in bryophytes has been reported multiple times (e.g. Dos Santos, Alvarenga, \& PôrtO, 2018; Hola, Vesalainen, Tesitel, \& Laaka-Lindberg , 2014; Horsley, Stark, \& Mcletchie, 2011; Stark, Mcletchie, \& Mishler, 2001). As a matter of fact, C. purpureushas often been used as a model system for sexual dimorphism in bryophytes exhibiting sex-specific differences in morphology, photosynthetic activity, organic volatile compound production, and even associated fungal community composition (Balkan, 2016; Rosenstiel, Shortlidge, Melnychenko, Pankow, \& Eppley, 2012; Shaw \& Beer, 1999; Shaw \& Gaughan, 1993; Slate, Rosenstiel, \& Eppley, 2017). However, sexual dimorphism in response to environmental stress has been addressed less frequently, and most research focused on the response to desiccation (Bowker et al., 2000; Marks et al., 2016; Moore, 2017; Stieha, Middleton, Stieha, Trott, \& Mcletchie, 2104;). Sexual dimorphism in response to the environment at the individual level (e.g. reduced individual fitness in one sex) can have consequences at the population level such as bias in population sex ratios limiting the frequency of sexual reproduction and genetic recombination, which might in turn restrict the capacity of plant populations to adapt to the environmental changes.

\subsection{Interspecies comparison}

Heavy metal accumulation and tolerance are two different quantitative traits that can vary in a continuous manner. Considering this, Goolsby \& Mason (2015) proposed that the interaction between these two traits brings about four categories of plants: (i) high accumulation and high tolerance, (ii) high accumulation and low tolerance, (iii) low accumulation and high tolerance, and (iv) low accumulation and low tolerance. Given 
the distinct ecological characteristics of our two study species, i.e. obligate vs. facultative metallophyte, we predicted that they would follow different strategies to cope with heavy metals. Thus, S. cataractae would follow a stress-tolerator strategy (category i) due to its high affinity for heavy metals, whereas C. purpureus would follow a stress-avoidance strategy (category iii) due to its lack of specialization but seemingly innate capacity to tolerate these pollutants. The tolerance-accumulation patterns found for S. cataractae suggested that heavily polluted populations of this species, i.e. Sc2 and Sc3, have different and metal-dependent strategies relative to each other. Sc2 behaved as a category iii "low accumulator and high tolerator" for $\mathrm{Cu}$ (limited accumulation in leaves) and Cd (lower total concentrations), whereas Sc3 behaved as a category iii "low accumulator and high tolerator" for $\mathrm{Cu}$ (limited accumulation in leaves) and as a category i "high accumulator and high tolerator" for Cd (higher total concentrations). For C. purpureus, we speculate that $\mathrm{Cp} 2 . f$, that hyperaccumulated $\mathrm{Cd}$ and showed greater tolerance relative to $\mathrm{Cp} 1$ and $\mathrm{Cp} 2 . \mathrm{m}$, behaved as category i "high accumulator and high tolerator" for $\mathrm{Cd}$, while $\mathrm{Cp} 1$ and $\mathrm{Cp} 2 . \mathrm{m}$ behaved as category ii "high accumulator and low tolerator" for $\mathrm{Cd}$. Because this species did not hyperaccumulate $\mathrm{Cu}$ and all populations reached similar final concentrations of this metal, we cannot assign them to any of the categories above.

Finally, we avoided further between-species comparisons due to inevitable differences in the experimental design between our two study species (e.g. how the treatments were applied, the actual concentrations of $\mathrm{Cd}$ and $\mathrm{Cu}$ used, and the developmental stages assessed - protonema vs gametophore). Nevertheless, from a broad perspective, our results showed that the tolerance-accumulation patterns of bryophytes are varied, and are congruent with predictions of differences between specialist vs. generalist strategies.

In conclusion, our results provide novel insights into the patterns of intraspecific differentiation for heavy metal accumulation and tolerance in bryophytes and the mechanisms underlying such differentiation. Our results support the unparalleled capacity of bryophytes to respond to environmental challenge despite potentially low levels of genetic variation and lack of previous exposure to stress, as well as the idea that intraspecific phenotypic variation is important for the fate of natural plant populations in the current context of environmental change.

\section{Conflict of interest}

The authors have no conflict of interest to declare.

\section{Author contributions}

M.T.B. designed the experiments with the advice of C.L.R. and C.A.; I.L. and M.G. contributed to microscopy data collection and analysis; M.T.B. performed data collection and analysis and wrote first draft of the manuscript; all authors critically reviewed and edited the manuscript.

\section{References}

Adlassnig W., Weiss Y.S., Sassmann S., Steinhauser G., Hofhansl F., Baumann N., Lichtscheidl I.K.,\& Lang I. (2016). The copper spoil heap Knappenberg, Austria, as a model for metal habitats - Vegetation, substrate and contamination. Science of The Total Environment, 563-564: 1037-1049

Aikawa Y., Nagano I., Sakamoto S., Nishiyama M., \& Matsumoto S. (1999). Contents of heavy metal elements in copper mosses: Scopelophila ligulata, Scopelophila cataractae, and Mielichhoferia japonica and their substrates. Soil Sci. Plant Nutr., 45: 835-842

Anderson J.T., Willis J.H., \& Mitchell-Olds T. (2011). Evolutionary genetics of plant adaptation. Trends Genet., 27(7): 258-266.

Antonovics J., Bradshaw A.D., \& Turner R.G. (1971). Heavy metal tolerance in plants. Adv Ecol Res $7: 1-85$.

Antreich S., Sassmann S., \& Lang I. (2016). Limited accumulation of copper in heavy metal adapted mosses. Plant Physiology and Biochemistry, 101: 141-148. 
Ares A., Aboal J.R., Carballeira A., Giordano S., Adamo P., Fernandez J.A. (2014). Moss bag biomonitoring: A methodological review. Science of the Total Environment, 475: 153-154

Ares Á., Itouga M., Kato Y., \& Sakakibara H. (2018). Differential metal tolerance and accumulation patterns of $\mathrm{Cd}, \mathrm{Cu}, \mathrm{Pb}$ and $\mathrm{Zn}$ in the liverwort Marchantia polymorpha L. Bull. Environ. Contam. Toxicol., 100(3): $444-450$

Arnold P.A., Kruuk L.E.B., \& Nicotra A.B. (2019). How to analyse plant phenotypic plasticity in response to a changing climate. New Phytol, 222: 1235-1241.

Atherton I., Bosanquet S., Lawley M. (2010). Mosses and Liverworts of Britain and Ireland - a field guide. Eds: Atherton I., Bosanquet S., Lawley M. Latimer Trend \& Co. Ltd, Plymouth, pp 354.

Baker A.J.M. (1981). Accumulators and excluders-strategies in the response of plants to heavy metals. J. Plant Nutr., 3: 643-654.

Baker A.J.M. (1987). Metal tolerance. New Phytologist, 106: 93-111.

Balkan M.A. (2016). Sex-specific fungal communities of the dioicous moss Ceratodon purpureus . Dissertations and Theses. Paper 2658.

Benjamini Y. \& Hochberg Y. (1995). Controlling the false discovery rate: a practical and powerful approach to multiple testing. Journal of the Royal Statistical Society Series B, 57, 289-300.

Bell G., Lechowicz M.J., Appenzeller A., Chandler M., DeBlois E., Jackson L., Mackenzie B., Preziosi R., Schallenberg M., \& Tinker N. (1993). The spatial structure of the physical environment. Oecologia, 96: 114-121.

Bellini E., Maresca V., Betti C., Castiglione M. R., Fontanini D., Capocchi A., Sorce C., Borso M., Bruno L., Sorbo S., Basile,A., Sanita di Toppi L. (2020). The moss Leptodictyum riparium counteracts severe cadmium stress by activation of glutathione transferase and phytochelatin synthase, but slightly by phytochelatins. International Journal of Molecular Sciences, 21(5): 1583.

Bisang I., \& Hedenas L. (2005). Sex ratio patterns in dioicous bryophytes re-visited. Journal of Bryology 27: 207-219.

Bothe H., \& Slomka A. (2017). Divergent biology of facultative heavy metal plants. Journal of Plant Physiology, 219: 45-61.

Box GE.P. \& Cox D.R. (1964). An Analysis of Transformations. Journal of the Royal Statistical Society. Series B (Methodological), 26(2): 211-252

Bowker M.A., Stark L.R., McLetchie D.N., \& Mishler B.D. (2000). Sex expression, skewed sex ratios, and microhabitat distribution in the dioecious desert moss Syntrichia caninervis (Pottiaceae). Am. J. Bot., 87(4): $517-526$.

Boyd R.S. (2004). Ecology of metal hyperaccumulation. New Phytologist, 162: 563-567.

Bradl H., editor (2002). Heavy Metals in the Environment: Origin, Interaction and Remediation Volume 6. London: Academic Press.

Bradshaw A.D. (1965). Evolutionary significance of phenotypic plasticity in plants. Adv. Genet., 13: $115-155$.

Bradshaw A.D. (2006). Unravelling phenotypic plasticity - why should we bother? New Phytologist 170: 644-648.

Briggs D. (1972). Population differentiation in Marchantia polymorpha L. in various lead pollution levels. Nature 238:166-167 
Brooks R.R., \& Malaisse F. (1985). The heavy metal-tolerant flora of southcentral Africa - a multidisciplinary approach. Balkema, Rotterdam, The Netherlands.

Brown D.H. \& House K.L. (1978). Evidence of a copper tolerant ecotype of the hepatic Solenostomum crenulatum. Ann. Bot., 42:1383-1392.

Brumelis G., \& Brown D.H. (1997). Movement of metals to new growing tissue in the moss Hylocomium splendens (Hedw.) BSG. Ann. Bot. 79: 679-686.

Burtscher W.P., List M.A., Payton A.C., McDaniel S.F., \& Carey S.B. (2020). Area from image analyses accurately estimates dry-weight biomass of juvenile moss tissue. bioRxiv 2020.03.20.000539

Cappa J.J., \& Pilon-Smits E.A.H. (2014). Evolutionary aspects of elemental hyperaccumulation. Planta, 239: $267-275$.

Carginale V., Sorbo S., Capasso C., Trinchella F., Cafiero G., Basile A. (2004). Accumulation, localisation, and toxic effects of cadmium in the liverwort Lunularia cruciata . Protoplasma, 223: 53-61.

Catalá M., Gasulla F., Pradas del Real A.E., García-Breijo F., Reig-Armiñana J., Barreno E. (2010). Fungalassociated NO is involved in the regulation of oxidative stress during rehydration in lichen symbiosis. BMC Microbiol. 10: 297.

Cogolludo J., Estébanez B., \& Medina N.G. (2017). The effects of experimentally supplied lead nitrate on three common moss Mediterranean moss species. Environm. Sci. Poll. Res., 24: 26194-26205.

Cove D.J., Perroud P.F., Charron A.J., McDaniel S.F., Khandelwal A., \& Quatrano R.S. (2009). Culturing the moss Physcomitrella patens . Cold Spring Harbor Laboratory Press, New York, NY.

Cuming A.C. (2009). Moss as a model system for plant stress responses. Chapter 2, In: Plant stress biology: from genomics to systems biology. Ed.: Hirt H. WILLEY-VCH Verlag GmbH \& Co. KGaA, Weinheim.

Crum H.A., \& Anderson L.E. (1981). Mosses of eastern North America. Columbia University Press, New York, NY.

Dos Santos W. L., Alvarenga L.D.P., \& PôrtO K. C. (2018). Sexual dimorphism, vegetative growth and reproductive investment in the rhizautoicous moss Fissidens flaccidus (Fissidentaceae, Bryopsida). Cryptogamie, Bryologie, 39 (2): 271-281.

Drenovsky R.E., Grewell B.J., D’Antonio C.M., Funk J.L., James J.J., Molinari N., Parker I.M. \& Richards C.L. (2012). A functional trait perspective on plant invasion: invasiveness to impacts in a changing world. Annals of Botany 110(1): 141-153.

Du Z.Y. \& Bramlage W.J. (1992). Modified thiobarbituric acid assay for measuring lipid oxidation in sugarrich plant-tissue extracts. J. Agric. Food Chem., 40: 1566-1570.

Dunham E.M. (1951). How to know the mosses: a popular guide to the mosses of the United States. Boston, MA: The Mosher Press.

Ernst W.O. (2006). Evolution of metal tolerance in higher plants. For. Snow Landsc. Res. 80, 3: 251-274

Esposito S., Loppi S., Monaci F., Paoli L., Vannini A., Sorbo S., Maresca V., Fusaro L., Asadi karam E., Lentini M., De Lillo A., Conte D., Cianciullo P., Basile A. (2018). In-field and in-vitro study of the moss Leptodictyum riparium as bioindicator of toxic metal pollution in the aquatic environment: ultrastructural damage, oxidative stress and HSP70 induction. PloS One, 13 (4): e0195717

Fernández J.A., Boquete M.T., Carballeira A., \& Aboal J.R. (2015). A critical review of protocols for moss biomonitoring of atmospheric deposition: sampling and sample preparation. Science of the Total Environment, 517: 132-150 
Geng Y., Pan X., Xu C., Zhang W.J., Li B., Chen J.K, Lu B.R:, Song Z.P. (2007). Phenotypic plasticity rather than locally adapted ecotypes allows the invasive alligator weed to colonize a wide range of habitats. Biol. Invasions, 9: 245-256.

Glime, J. M. (2017a). Limiting Factors and Limits of Tolerance. Chapt. 6-1. In: Glime, J. M. Bryophyte Ecology. Volume 1.http://www.bryoecol.mtu.edu/

Glime, J. M. (2017b). Life Cycles: Surviving Change. Chapt. 2-2. In: Glime, J. M. Bryophyte Ecology. Volume 1.http://www.bryoecol.mtu.edu/

Goolsby E.W., \& Mason C.M. (2015). Toward a more physiologically and evolutionarily relevant definition of metal hyperaccumulation in plants. Front Plant Sci., 6: 33.

He Z.L., Yang X.E., \& Stoffella P.J. (2005). Trace elements in agroecosystems and impacts on the environment. J Trace Elem Med Biol, 19(2-3): 125-40.

Heath R.L. \& Packer K. (1968). Photoperoxidation in isolated chloroplast. I. Kinetics and stoichiometry of fatty acid peroxidation. Arch. Biochem. Biophys. 125, 189.

Henn J.J., Buzzard V., Enquist B.J., Halbritter A.H., Klanderud K., Maitner B.S., Michaletz S.T., Pötsch C., Seltzer L., Telford R.J., Yang Y., Zhang L., Vandvik V. (2018). Intraspecific trait variation and phenotypic plasticity mediate alpine plant species response to climate change. Frontiers in Plant Science, 9: 1548

Hola E., Vesalainen T., Tesitel J., \& Laaka-Lindberg S. (2014). Sex ratio, sex-specific pattern in vegetative growth and gemma production in an aquatic liverwort, Scapania undulata (Marchantiophyta: Scapaniaceae). Botanical journal of the linnean society, 175(2): 229-241.

Horsley K., Stark L.R., \& Mcletchie D.N. (2011). Does the silver moss Bryum argenteum exhibit sex-specific patterns in vegetative growth rate, asexual fitness or prezygotic reproductive investment? Annals of Botany, 107(6): 897-907.

Hothorn T., Bretz F., \& Westfall P. (2008). Simultaneous inference in general parametric models. Biometrical Journal 50(3): 346-363.

Itouga M., Hayatsu M., Sato M., Tsuboi Y., Kato Y., Toyooka K., Suzuki S., Nakatsuka S., Kawakami S., Kikuchi, J., Sakakibara H. (2017). Protonema of the moss Funaria hygrometrica can function as a lead (Pb) adsorbent. PLoS One, 12(12): e0189726.

Ireland R.R. (1982). Moss flora of the Maritime Provinces. Publications in Botany No. 13. [Ottawa, ON]: National Museum of Natural Sciences. 738 p. [18662]

Jarup L. (2003). Hazards of heavy metal contamination. Br. Med. Bull. 68, 167-182.

Jules E.S, \& Shaw A.J. (1994). Adaptation to metal-contaminated soils in populations of the moss, Ceratodon purpureus : vegetative growth and reproductive expression. American Journal of Botany, 81(6): 791-797.

Kelly S.A., Panhuis T.M., \& Stoehr A.M. (2012). Phenotypic plasticity: molecular mechanisms and adaptive significance. Compr. Physiol., 2(2): 1417-1439.

Kobayashi F., Kofuji R., Yamashita Y., \& Nakamura Y. (2006). A novel treatment system of wastewater contaminated with copper by a moss, Biochem. Eng. J. 28: 295-298.

Konno H., Nakashima S., \& Katoh K. (2010). Metal-tolerant mossScopelophila cataractae accumulates copper in the cell wall pectin of the protonema. J Plant Physiol.,167(5): 358-364

Kovácik J., Dresler S., \& Babula P. (2020). Long-term impact of cadmium in protonema cultures of Physcomitrella patens . Ecotoxicology and Environmental Safety, 193: 110333.

Kruckeberg A.R. \& Kruckeberg, A.L. (1990). Endemic metallophytes: their taxonomic, genetic, and evolutionary attributes. In: Heavy metal tolerance in plants: evolutionary aspects, Ed. Shaw A.J. pp.301-312 
Krzeslowska M., Lenartowska M., Mellerowicz E.J., Samardakiewicz S., Wozny A. (2009). Pectinous cell wall thickenings formation - a response of moss protonemata cells to lead. Environ Exp Bot, 65: 119-31.

Lázaro-Nogal A., Matesanz S., Godoy A., Pérez-Trautman F., Gianoli E. and Valladares F. (2015). Environmental heterogeneity leads to higher plasticity in dry-edge populations of a semi-arid Chilean shrub: insights into climate change responses. J Ecol, 103: 338-350. DOI:10.1111/1365-2745.12372

Lewis S.L., \& Maslin, M.A. (2015). Defining the Anthropocene. Nature, 519(7542): 171-180

Liang L., Tang H., Deng Z., Liu Y., Chen X., Wang H. (2018). Ag nanoparticles inhibit the growth of the bryophyte, Physcomitrella patens . Ecotoxicol Environ Saf., 164: 739-748.

Macnair M.R. (1987). Heavy metal tolerance in plants: a model evolutionary system. Trends in Ecology and Evolution, 2(12): 354-359.

Maestri E., Marmiroli M., Visioli G., \& Marmiroli N. (2010) Metal tolerance and hyperaccumulation: costs and trade-offs between traits and environment. Environ Exp Bot 68:1-13

Marks R.A., Burton J.F., \& Mcletchie D.N. (2016). Sex differences and plasticity in dehydration tolerance: insight from a tropical liverwort. Annals of Botany, 118(2): 347-356

McDaniel S.F., Atwood J., \& Burleigh J.G. (2012). Recurrent evolution of dioecy in bryophytes. Evolution, 67(2): $567-572$.

McIntyre P.J., \& Strauss S.Y. (2014). Phenotypic and transgenerational plasticity promote local adaptation to sun and shade environments. Evol. Ecol., 28: 229-246.

Melo V.F., Batista A.H., Gilkes R.J., \& Rate A.W. (2016). Relationship between heavy metals and minerals extracted from soil clay by standard and novel acid extraction procedures. Environ. Monit. Assess., 188, 668.

Moore J.D. (2017). Sexual dimorphism in the moss Bryum argenteumand its implications for sex ratio bias. Theses and Dissertations, Biology, 43.

Nakajima H., Itoh K., Otake H., \& Fujimoto K. (2011). Spectral properties of the Cu-hyperaccumulating moss Scopelophila cataractae. Journal of Photochemistry and Photobiology B: Biology, 104(3): 467-472

Nicotra A.B., Atkin O.K., Bonser S.P., Davidson A.M., Finnegan E.J., Mathesius U., Poot P., Purugganan M.D., Richards C.L., Valladares F., van Kleunen M. (2010). Plant phenotypic plasticity in a changing climate. Trends in Plant Science 15: 684-692

Nomura T., \& Haezawa S. (2011). Regulation of gemma formation in the copper moss Scopelophila cataractae by environmental copper concentrations. J. Plant Res., 124: 631-638.

Onianwa P.C. (2001) Monitoring atmospheric metal pollution: a review of the use of mosses as indicators. Environ Monit Assess 71:13-50

Parmesan C., \& Hanley M.E. (2015). Plants and climate change: complexities and surprises. Annals of Botany, 11(6): 849-864.

Pauwels M., Frerot H., Bonnin I., \& Saumitou-Laprade P. (2006). A broad-scale analysis of population differentiation for Zn tolerance in an emerging model species for tolerance study, Arabidopsis halleri (Brassicaceae). Journal of Evolutionary Biology, 19: 1838-180.

Pigliucci M. (2001). Environmental Heterogeneity: Temporal and Spatial. eLS. DOI: 10.1038/npg.els.0001766.

R Core Team, 2018. R: A language and environment for statistical computing. R Foundation for Statistical Computing, Vienna, Austria. https://www.R-project.org/ 
RStudio Team (2019). RStudio: Integrated Development for R. RStudio, Inc., Boston, MA URLhttp://www.rstudio.com/

Reeves D.R., Baker A.J.M., Borhidi A., \& Berazaín R. (1996). Nickel-accumulating plants from the ancient serpentine soils of Cuba. New Phytologist, 133: 217-224

Reeves D.R., Baker A.J., Jaffré T., Erskine P.D., Echevarria G., \& van der Ent A. (2017). A global database for plants that hyperaccumulate metal and metalloid trace elements. New Phytologist, 218: 407-411.

Renzaglia K.S., Duff R.J.T., Nickrent D.L., \& Garbary D.J. (2000). Vegetative and reproductive innovations of early land plants: implications for a unified phylogeny. Philos Trans R Soc Lond B Biol Sci., 355(1398): 769-793.

Renzaglia K.S., Schuette S., Duff R.J., Ligrone R., Shaw A.J., Mishler B.D., \& Duckett J.G. (2007). Bryophyte phylogeny: advancing the molecular and morphological frontiers. The Bryologist 110(2): 179-213

Richards C.L., Bossdorf O., Muth N.Z., Gurevitch J., \& Pigliucci M. (2006). Jack of all trades, master of some? On the role of phenotypic plasticity in plant invasions. Ecology Letters, 9: 981-993.

Richards C.L., Walls R., Bailey J.P., Parameswaran R., George T., \& Pigliucci M. (2008). Plasticity in salt tolerance traits allows for invasion of salt marshes by Japanese knotweed s.l. (Fallopia japonica and $F$. xbohemica, Polygonaceae). American Journal of Botany 95: 931-942.

Richards C.L., White S.N., McGuire M.A., Franks S.J., Donovan L.A., Mauricio R. (2010). Plasticity, not adaptation to salt level, explains variation along a salinity gradient in a salt marsh perennial. Estuaries and Coasts: Special Feature on Genetic Structure and Adaptation in Coastal Ecosystems 33: 840-852.

Richter C., \& Dainty J. (1989). Ion behaviour in plant cell walls. Characterization of the Sphagnum russowii cell wall ion exchanger. Can J Bot, 67: 451-9.

Rosenstiel T., Shortlidge E., Melnychenko A., Pankow J.F., \& Eppley S.M. (2012). Sex-specific volatile compounds influence microarthropod-mediated fertilization of moss. Nature, 489: 431-433.

Sandhi A., Landberg T., \& Greger M. (2018). Phytofiltration of arsenic by aquatic moss (Warnstorfia fluitans ). Environ. Pollut., 237: 1098-1105.

Satake K., Shibata K., Nishikawa M., \& Fuwa K. (1998). Copper accumulation and location in the moss Scopelophila cataractae, J. Bryol. 15: 353-376.

Schlichting C.D. (1986). The evolution of phenotypic plasticity in plants. Annu. Rev. Ecol. Syst. 17: 667-693.

Schneider C.A., Rasband W.S., \& Eliceiri K.W. (2012). NIH Image to ImageJ: 25 years of image analysis. Nature methods 9(7): 671-675.

Shaw A.J. (1987). Evolution of heavy metal tolerance in bryophytes. II. An ecological and experimental investigation of the "Copper Moss," Scopelophila cataractae (Pottiaceae). Amer. J. Bot. 74(6): 813-821. 1987

Shaw A.J., Antonovics J., \& Anderson L.E. (1987). Inter- and intraspecific variation of mosses in tolerance to copper and zinc. Evolution, 41(6): 1312-1325.

Shaw A.J. (1988). Genetic variation for tolerance to copper and zinc within and among populations of the moss, Funaria hygrometricaHedw. New Phytologist, 109: 211-222.

Shaw A. J. (1990). Heavy metal tolerance in plants: evolutionary aspects. CRC Press, Boca Raton, Florida.

Shaw A.J., Jules E.S., \& Beer S.C. (1991). Effects of metals on growth, morphology, and reproduction of Ceratodon purpureus . The Bryologist, 94(3): 270-277. 
Shaw A.J. \& Gaughan J.F. (1993). Control of sex ratios in haploid populations of the moss, Ceratodon purpureus. American Journal of Botany, 80(5): 584-591.

Shaw A.J. (1993a). Population biology of the rare copper mossScopelophila cataractae . Am J Bot 80(9):1034-1041

Shaw A.J. (1993b). Morphological uniformity among widely disjunct populations of the rare "copper moss," Scopelophila cataractae(Pottiaceae). Systematic Botany, 18(3): 525-537

Shaw A.J. (1994). Adaptation to metals in widespread and endemic plants. Environmental health perspectives, 102 Suppl 12(Suppl 12), 105-108.

Shaw A.J. (1995). Genetic biogeography of the rare "copper moss" Scopelophila cataractae (Pottiaceae). Pl. Syst. Evol., 197: 43-58.

Shaw A.J. \& Beer S.C. (1999). Life-history variation in gametophyte populations of the moss Ceratodon purpureus (Ditrichaceae). Am. J. Bot., 86: 512-521

Sidhu M., \& Brown D.H. (1996). A new laboratory technique for studying the effects of heavy metals on bryophyte growth. Ann. Bot. 78: 711-717.

Simms E.L. (2000). Defining tolerance as a norm of reaction. Evolutionary Ecology, 14: 563-570.

Singh O.V., Labana S., Pandey G., Budhiraja R., \& Jain R.K. (2003). Phytoremediation: an overview of metallic ion decontamination from soil. Appl Microbiol Biotechnol 61: 405-412.

Slate M.L., Rosenstiel T.N., \& Eppley S.M. (2017). Sex-specific morphological and physiological differences in the moss Ceratodon purpureus (Dicranales). Ann Bot., 120(5): 845-854.

Stanković J.D., Sabovljević A.D., \& Sabovljević M.S. (2018). Bryophytes and heavy metals: a review, Acta Botanica Croatica, 77(2), 109-118

Stark L.R., Mcletchie D.N., \& Mishler B. (2001). Sex expression and sex dimorphism in sporophytic populations of the desert mossSyntrichia caninervis . Plant Ecology, 157(2): 183-196.

Steinnes E., Ruhling A., Lippo H., \& Makinen A. (1997). Reference materials for large scale metal deposition surveys. Accred. Qual. Assur. 2: 243-249.

Stieha C.R., Middleton A.R., Stieha J.K., Trott S.H., \& Mcletchie D.N. (2014). The dispersal process of asexual propagules and the contribution to population persistence in Marchantia inflexa (Marchantiaceae). American Journal of Botany, 101: 348-356

Sultan S. E. (1987). Evolutionary implications of phenotypic plasticity in plants. Evol. Biol. 21: 127-178.

Sultan S.E. (2000). Phenotypic plasticity for plant development, function and life history. Trends in Plant Science, 5(12): 537-542.

Sut-Lohmanna M., Jonczakb J., \& Raaba T. (2020). Phytofiltration of chosen metals by aquarium liverwort (Monosoleum tenerum ). Ecotoxicology and Environmental Safety, 30: 109844.

Tilman D. \& Lehman C. (2001). Human-caused environmental change: impact on plant diversity and evolution. Proc. Natl. Acad. Sci. USA 98(10): 5433-5440.

Turner K.G., Fréville H., \& Rieseberg L.H. (2015). Adaptive plasticity and niche expansion in an invasive thistle. Ecol. Evol., 5: 3183-3197.

Vallack,H.W., \& Rypdal K. (2019). The Global Atmospheric Pollution Forum Air Pollutant Emission Inventory Manual. Version 6.0 May 2019 revision.

Vanderpoorten A., \& Goffinet B. (2009). Introduction to Bryophytes. Eds. Vanderpoorten A. and Goffinet B. Cambridge University Press. 
Verbruggen N., Hermans C., \& Schat H. (2009). Molecular mechanisms of metal hyperaccumulation in plants. New Phytologist, 181: 759-776.

Vitousek P.M., Mooney H.A., Lubchenco J., \& Melillo J.M. (1997). Human domination of Earth's ecosystems. Science, 277: 494-499.

Wells J.M., \& Brown D.H. (1996). Mineral nutrient recycling within shoots of the moss Rhytidiadelphus squarrosus in relation to growth. J. Bryol. 19: 1-17.

Whiting, S.N., Reeves, R.D., Richards, D., Johnson, M.S., Cooke, J.A., Malaisse, F., Paton, A., Smith, J.A.C., Angle, J.S., Chaney, R.L., Ginocchio, R., Jaffré, T., Johns, R., McIntyre, T., Purvis, O.W., Salt, D.E., Schat, H., Zhao, F.J. \& Baker, A.J.M. (2004), Research priorities for conservation of metallophyte biodiversity and their potential for restoration and site remediation. Restoration Ecology, 12: 106-116.

Wickland D.E. (1984). Vegetation patterns in derelict heavy metal mine sites in the North Carolina Piedmont. Ph.D. dissertation, University of North Carolina, Chapel Hill.

Willi Y. \& Hoffmann A.A. (2009). Demographic factors and genetic variation influence population persistence under environmental change. Journal of Evolutionary Biology, 22: 124-133.

Williams D.G., Mack R.N., \& Black R.A. (1995). Ecophysiology of introduced Pennisetum setaceum on Hawaii: the role of phenotypic plas- ticity. Ecology 76: 1569-1580.

Wright J.W., Stanton M.L., \& Scherson R. (2006) Local adaptation to serpentine and non-serpentine soils in Collinsiasparsiflora. Evol Ecol Res 8:1-21

Table 1: Summary of the statistical analyses carried out for each of the datasets in this study. For the common garden experiments, tests were done by comparing the controls with each of the treatments performed,i.e. controls vs $\mathrm{Cu}$-treated plants in common garden- $\mathrm{Cu}$, and controls vs $\mathrm{Cd}$-treated plants in common garden-Cd. glm: generalized linear model; NA(KW): no glm performed (due to the low number of replicates), instead, a kruskal wallis $(\mathrm{KW})$ test was used to compare control vs. treated plants without considering the population effect.

\begin{tabular}{|c|c|c|c|c|}
\hline Experiment & Moss species & Measurement & Dependent variable & glm family (link) \\
\hline \multirow[t]{7}{*}{ Field samples } & \multirow[t]{9}{*}{ Scoelophila cataractae } & \multirow[t]{3}{*}{ Plant morphology } & Plant length (mm) & gamma (log) \\
\hline & & & Leaf length $(\mathrm{mm})$ & gamma (log) \\
\hline & & & Leaf width (mm) & gamma (log) \\
\hline & & \multirow[t]{4}{*}{ HM contents } & Total $\mathrm{Cu}(\mu \mathrm{g} g-1)$ & gamma (log) \\
\hline & & & Total Cd ( $\mu \mathrm{g} g-1)$ & gamma (log) \\
\hline & & & Relative $\mathrm{Cu}(\%)$ & gamma (log) \\
\hline & & & Relative Cd (\%) & gamma (log) \\
\hline \multirow[t]{2}{*}{ Soil field samples } & & \multirow[t]{2}{*}{ HM contents } & Total $\mathrm{Cu}(\mu \mathrm{g} g-1)$ & gamma (log) \\
\hline & & & Total Cd ( $\mu \mathrm{g} g-1)$ & $\operatorname{gamma}\left(1 / \mathrm{mu}^{\wedge} 2\right)$ \\
\hline \multirow[t]{11}{*}{ Common garden $\mathrm{Cu}$} & \multirow[t]{7}{*}{ Scoelophila cataractae } & \multirow[t]{3}{*}{ Plant morphology } & Plant length (mm) & gamma (log) \\
\hline & & & Leaf length (mm) & gamma (log) \\
\hline & & & Leaf width (mm) & gamma (log) \\
\hline & & \multirow[t]{3}{*}{ HM contents } & Total $\mathrm{Cu}(\mu \mathrm{g} g-1)$ & gamma (log) \\
\hline & & & Relative $\mathrm{Cu}$ in leaves (\%) & gamma (log) \\
\hline & & & Relative $\mathrm{Cu}$ in stem (\%) & gamma (log) \\
\hline & & Oxidative damage & MDA levels & inverse.gaussian $(\log )$ \\
\hline & \multirow[t]{4}{*}{ Ceratodon purpureus } & Protonemal gowth & Growth (mm2) & gausian (inverse) \\
\hline & & Oxidative damage & MDA levels & gamma (log) \\
\hline & & HM contents & Total ( $\mu g$ g-1) & $\mathrm{NA}(\mathrm{KW})$ \\
\hline & & & Relative (\%) & gamma (log) \\
\hline Common garden $\mathrm{Cd}$ & Scoelophila cataractae & Plant morphology & Plant length $(\mathrm{mm})$ & gamma (log) \\
\hline
\end{tabular}

No

No

No

No

No

Yes

Yes

No

No

No

No

No

No

No

No

No

Yes

No

No

No 


\begin{tabular}{|c|c|c|c|c|c|}
\hline Experiment & Moss species & Measurement & Dependent variable & glm family (link) & $\operatorname{Tr}$ \\
\hline & \multirow{10}{*}{ Ceratodon purpureus } & \multirow{5}{*}{ HM contents } & Leaf length(mm) & gamma (log) & $\mathrm{No}$ \\
\hline & & & Leaf width (mm) & gamma (log) & $\mathrm{N}$ \\
\hline & & & Total Cd ( $\mu \mathrm{g} g-1)$ & gamma (log) & \\
\hline & & & Relative Cd in leaves (\%) & gamma (log) & \\
\hline & & & Relative Cd in stem (\%) & gamma (log) & \\
\hline & & Oxidative damage & MDA levels & inverse.gaussian $(\log )$ & \\
\hline & & Protonemal gowth & Growth (mm2) & gausian (inverse) & \\
\hline & & Oxidative damage & MDA levels & gamma (log) & \\
\hline & & HM contents & Total ( $\mu g \mathrm{~g}-1)$ & $\mathrm{NA}(\mathrm{KW})$ & \\
\hline & & & Relative (\%) & gamma (log) & \\
\hline
\end{tabular}

\section{Figure captions}

Figure 1: Scopelophila catatactae and soil collected within the copper mine. Bar plots (mean + standard deviation with 3 replicates) of the total concentrations of $\mathrm{Cu}$ and $\mathrm{Cd}$ in soil (A, D) and plants of (B, E) where numbers inside the bars represent mean concentrations $\left(\mu \mathrm{g} \mathrm{g}^{-1}\right)$. Boxplots of the relative concentrations of $\mathrm{Cu}$ and $\mathrm{Cd}$ in moss samples $(\mathrm{C}, \mathrm{F})(\mathrm{n}=12 ; \%$ by weight). Panels $\mathrm{G}, \mathrm{H}$, and I depict the morphological measurements (plant length, leaf length, and leaf width in $\mathrm{mm}$ ) performed in $\mathrm{n}=50$ plants from each of the populations of $S$. cataractae collected in the field. Black stars inside the boxplots represent mean values. Letters inside the graph boxes represent the results of the multiple pairwise comparisons, with means sharing a letter not differing significantly. Green and red color represent populations sampled at the edges and the center of the mine respectively.

Figure 2: Scopelophila catatactae response to $\mathrm{Cu}$ and $\mathrm{Cd}$ treatment. Bar plots (mean $\mu \mathrm{g} \mathrm{g} \mathrm{g}^{-1}$ indicated + standard deviation with 3 replicates) of the total concentrations of $\mathrm{Cu}$ in control and $\mathrm{Cu}$-treated (A), and of $\mathrm{Cd}$ in control and Cd-treated (D) plants of $S$. catatactae cultured in the laboratory. Boxplots of the relative concentrations $(\mathrm{n}=12$; weight $\%)$ of $\mathrm{Cu}$ in leaves and stems of control and $\mathrm{Cu}$-treated plants $(\mathrm{B}$, $\mathrm{C}$ respectively), and of $\mathrm{Cd}$ in leaves and stems of control and Cd-treated plants (E, F respectively). Black stars inside the boxplots represent mean values. Letters inside the graph boxes represent the results of the multiple pairwise comparisons, with means sharing a letter do not differing significantly. Green and red color represent populations sampled at the edges and the center of the mine respectively.

Figure 3: Scopelophila catatactae response to $\mathrm{Cu}$ and $\mathrm{Cd}$ treatment. Boxplots $(\mathrm{n}=10)$ of plant length, leaf length, and leaf width (mm) in control and Cu-treated (A, B, C), and in control and Cd-treated (E, F, G) plants of $S$. catatactae cultured in the laboratory. Black stars inside the boxplots represent mean values. Bar plots (mean $\mu \mathrm{M}$ indicated \pm standard deviation with 3 replicates except for controls whose $\mathrm{n}=2$ for Sc3 and Sc4 and $n=1$ for Sc1) of the concentration of malondialdehyde (MDA) in control and Cu-treated (D), and in control and $\mathrm{Cd}$-treated $(\mathrm{H})$ plants. Letters inside the graph boxes represent the results of the multiple pairwise comparisons, with means sharing a letter not differing significantly. Green and red colors represent populations sampled at the edges and the center of the mine respectively.

Figure 4: Ceratodon purpureus response to $\mathrm{Cu}$ and $\mathrm{Cd}$ treatment. Bar plots (mean $\mu \mathrm{g} \mathrm{g}^{-1}$ indicated + standard deviation with 2 replicates except for $\mathrm{Cp} 1$-Cd with $\mathrm{n}=1$ ) of the total concentrations of $\mathrm{Cu}$ in control and $\mathrm{Cu}-$ treated (A) and in control and Cd-treated (B) plants of C. purpureus cultured in the laboratory. Boxplots of the relative concentrations $\left(\mathrm{n}=10\right.$; by weight \%) and of the protonemal growth $\left(\mathrm{mm}^{2} ; \mathrm{n}=35\right)$ in control and $\mathrm{Cu}$-treated (B and $\mathrm{C}$ ) and in control and Cd-treated ( $\mathrm{F}$ and $\mathrm{G}$ ) plants. Bar plots (mean $\mu \mathrm{M}$ indicated + standard deviation with 10 replicates) of the concentration of malondialdehyde (MDA) in control and $\mathrm{Cu}-$ treated (D) and in control and $\mathrm{Cd}$-treated $(\mathrm{H})$ plants. Black stars inside the boxplots represent mean values. Letters inside the graph boxes represent the results of the multiple pairwise comparisons, with means sharing a letter not differing significantly. Green and red color represent control and treated samples respectively. 

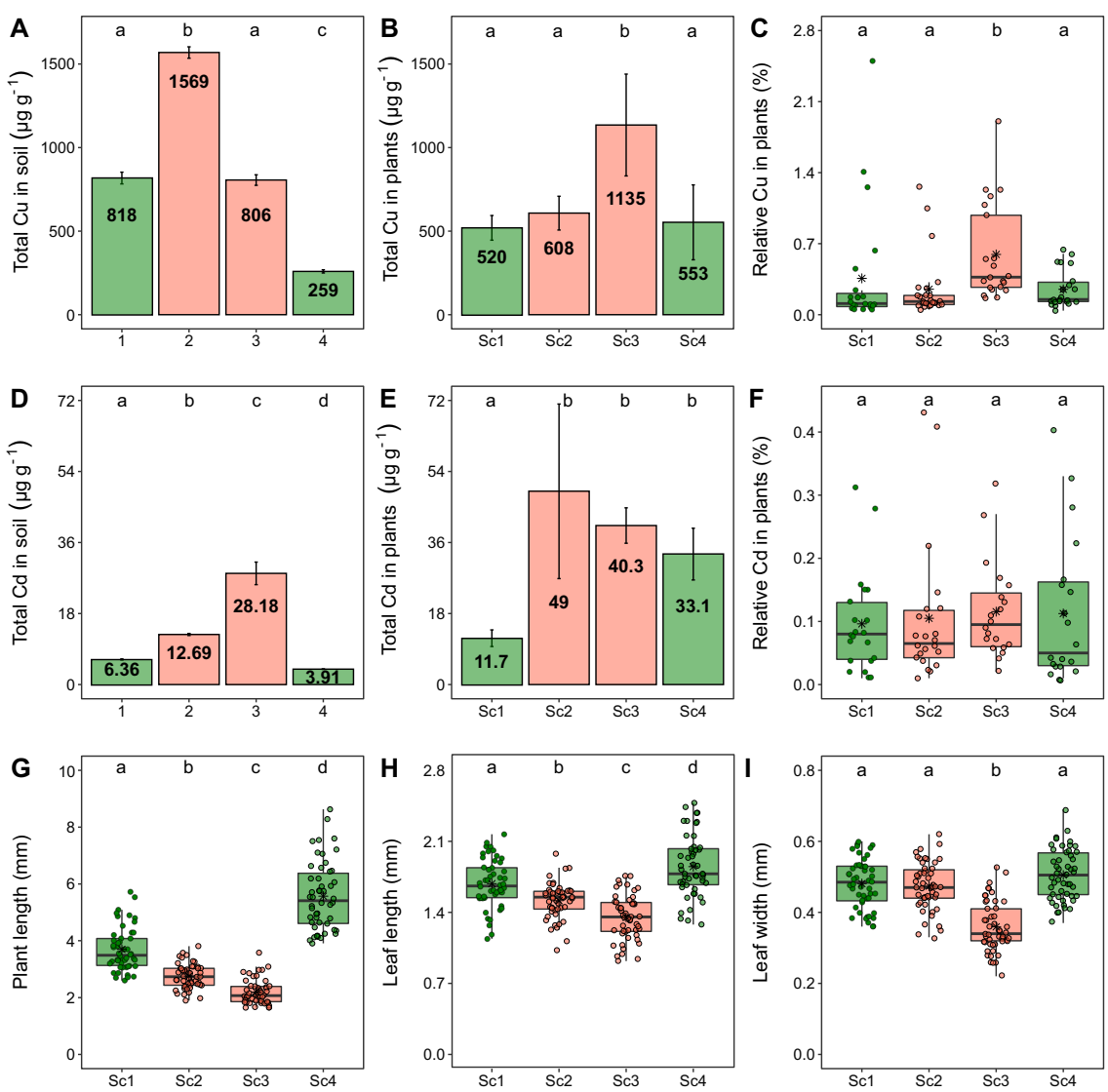

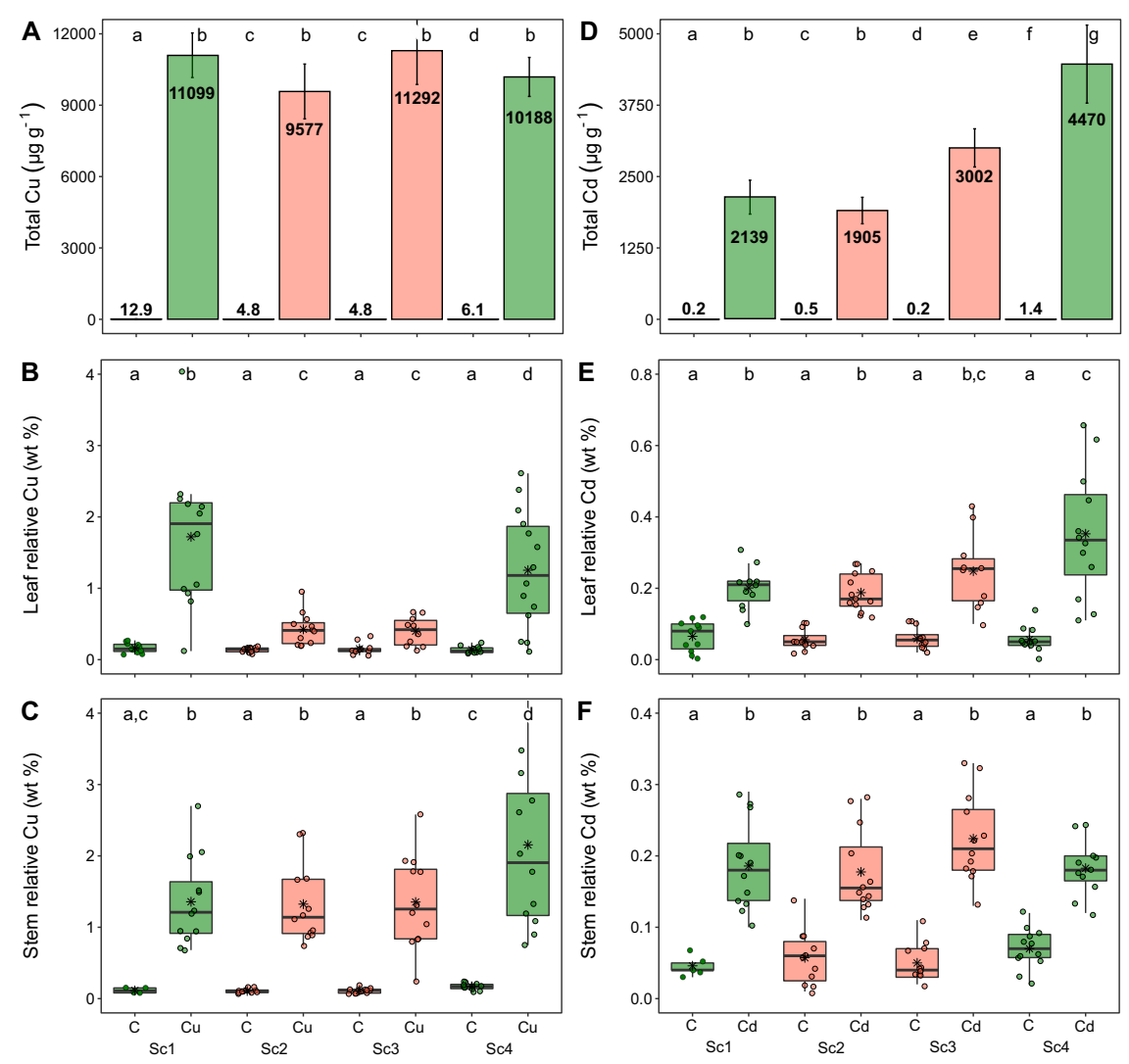

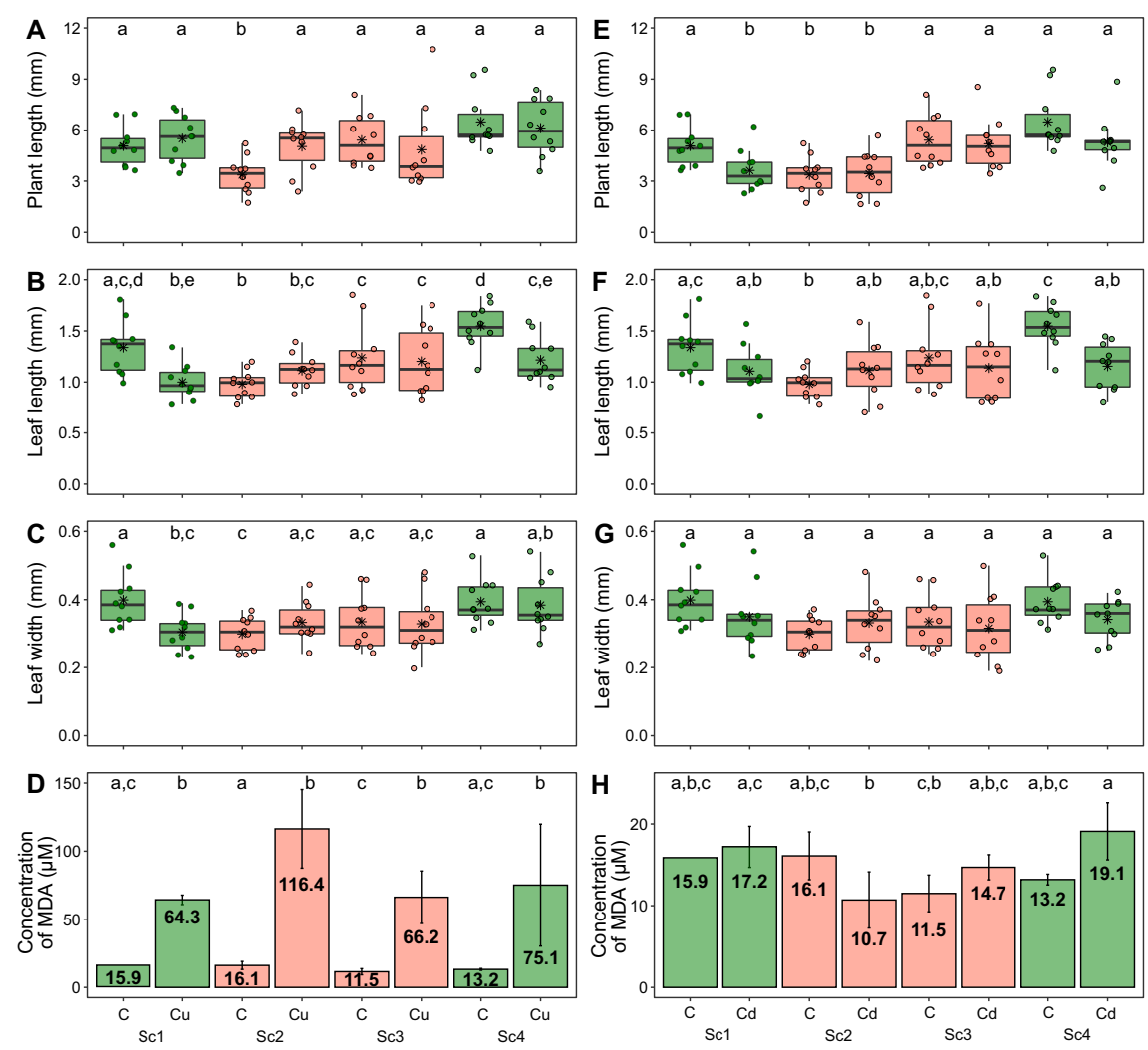

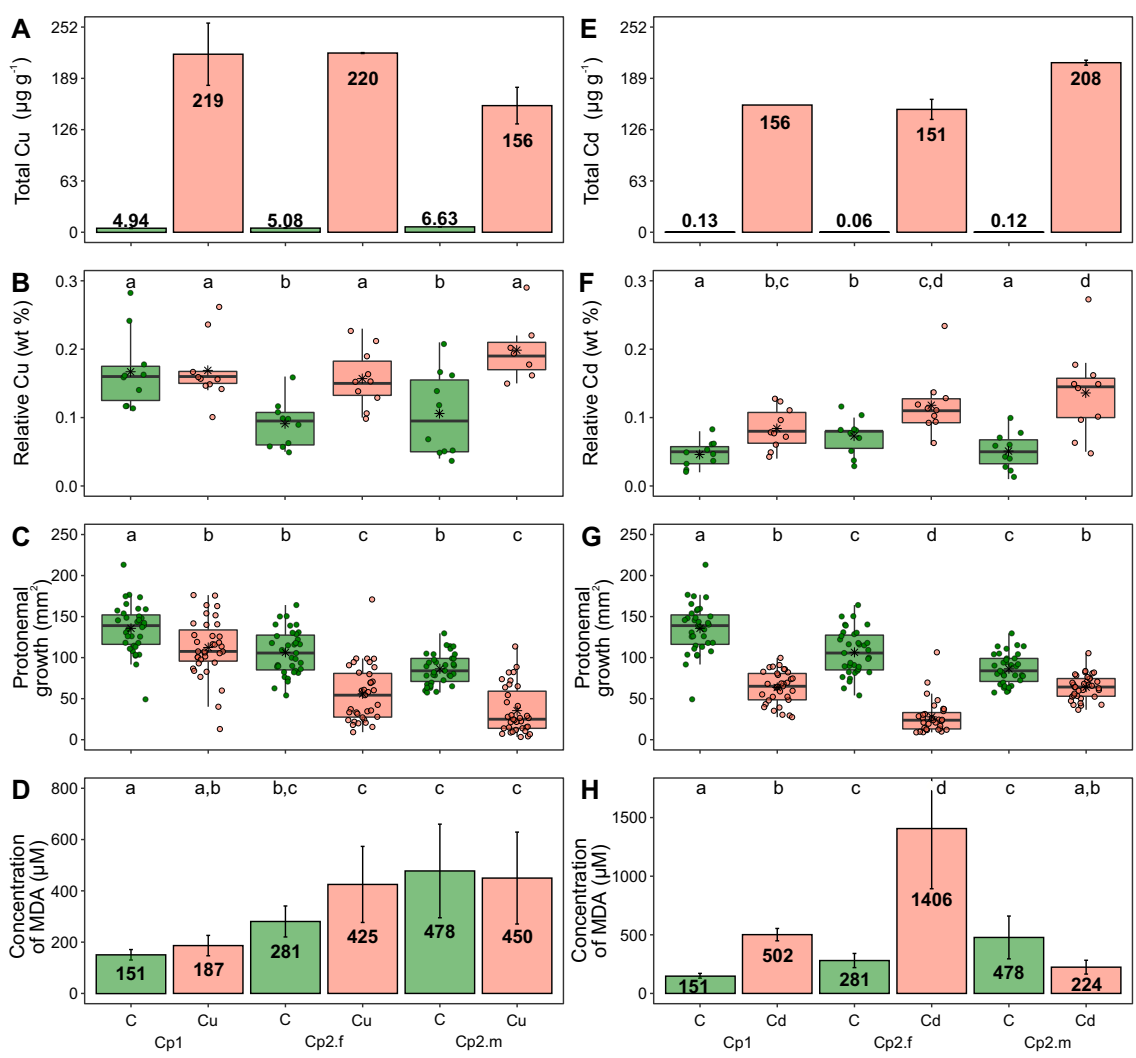